\title{
Regioselective Electrophilic Fluorination of Rationally Designed Imidazole
} Derivatives

\author{
Klaus Albertshofer* and Neelakandha S. Mani \\ Janssen Research \& Development, LLC, 3210 Merryfield Row, San Diego, California 92121, \\ United States \\ kalberts@its.jnj.com
}

\section{Supporting Information}

\section{Table of Contents}

1. Screen of Fluorinating Reagents $\quad$ S2

2. ${ }^{1} \mathrm{H}-,{ }^{13} \mathrm{C}$-, and $19^{\mathrm{F}}$-NMR Spectra $\quad$ S3 


\section{Screen of Fluorinating Reagents}

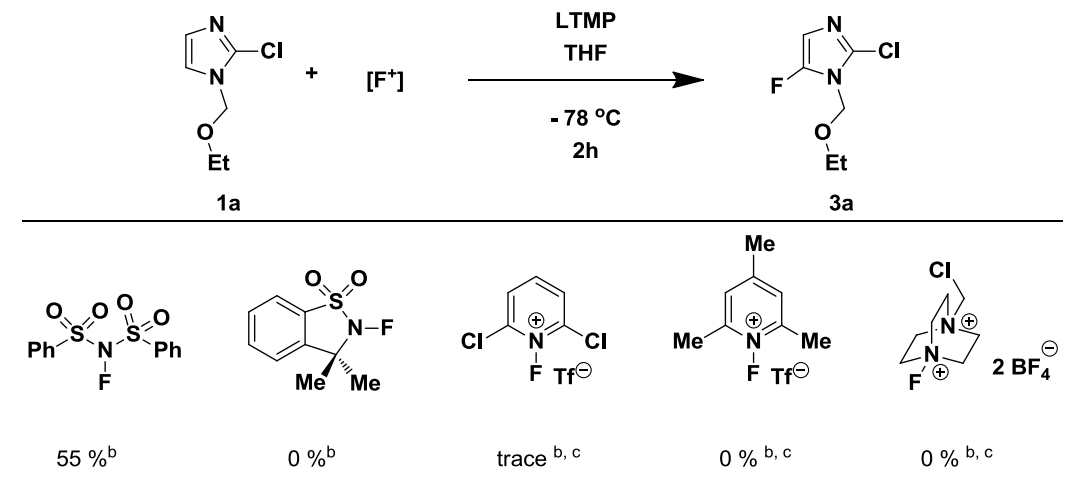

${ }^{a}$ Reaction conditions: 1a $(2.49 \mathrm{mmol}, 1$ equiv. $)$, fluorinating reagent $\left(\mathrm{F}^{+}\right)(2.74 \mathrm{mmol}$, 1.6 equiv.), LTMP (4.98 mmol, 2 equiv.), THF (22 ml). ${ }^{\mathrm{b}}$ Percent conversion determined by ${ }^{1} \mathrm{H}$ NMR of the crude reaction mixture. ${ }^{\mathrm{c}}\left(\mathrm{F}^{+}\right)(2.74 \mathrm{mmol} 1.1$ equiv.). 
2-chloro-1-(ethoxymethyl)-5-fluoro-1H-imidazole (3a).

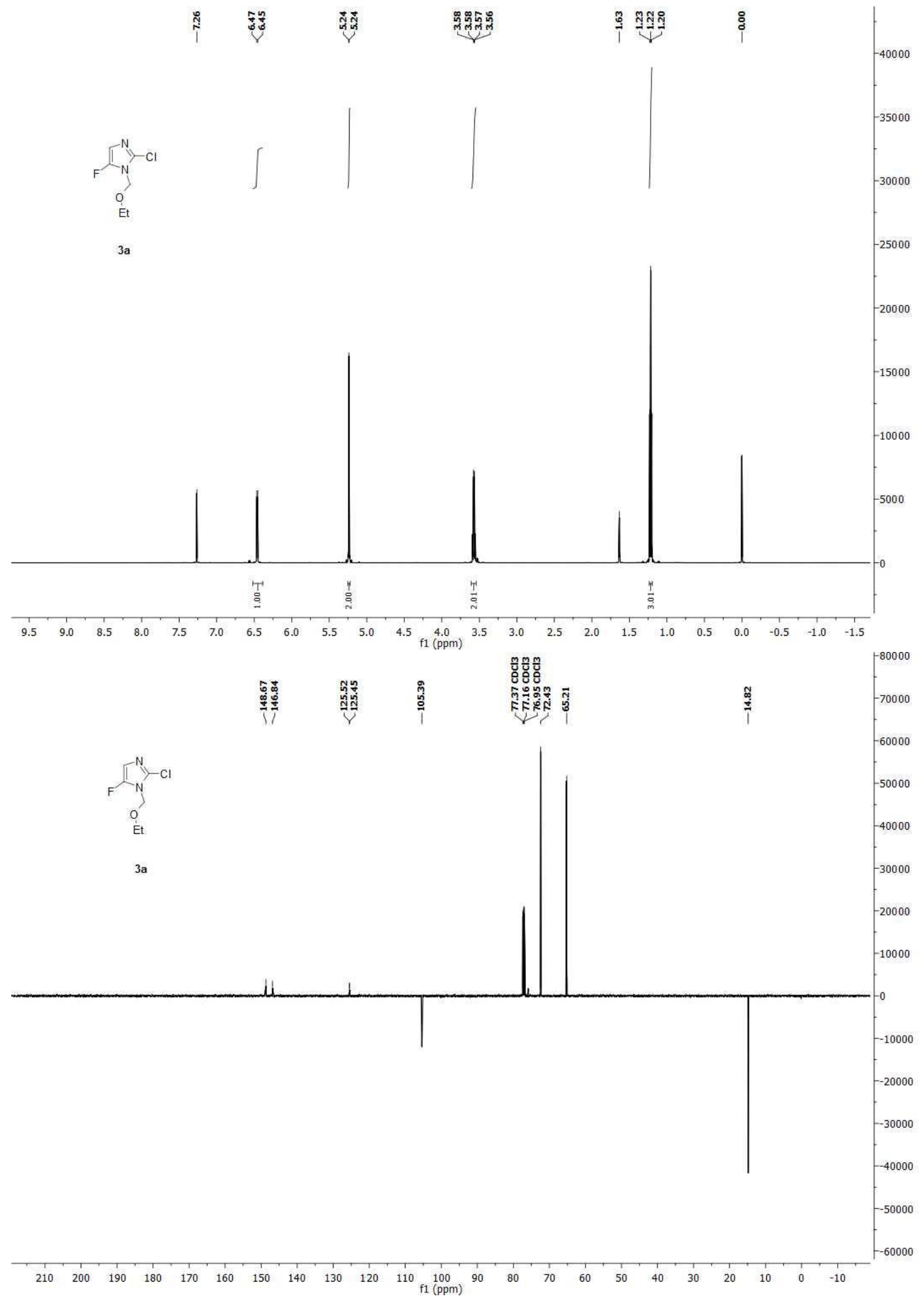




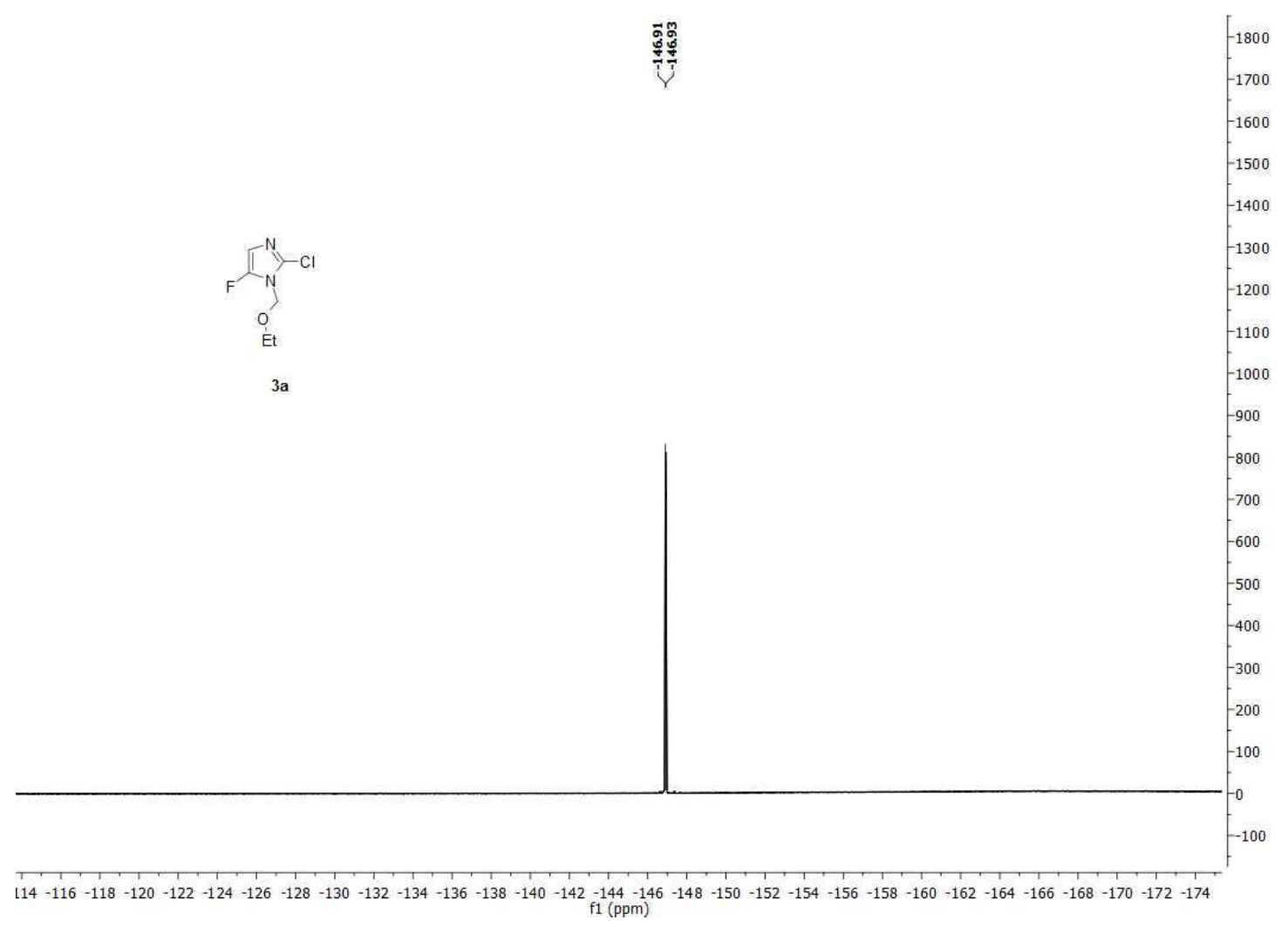

2-chloro-5-fluoro-1-((2-(trimethylsilyl)ethoxy)methyl)-1H-imidazole (3b).

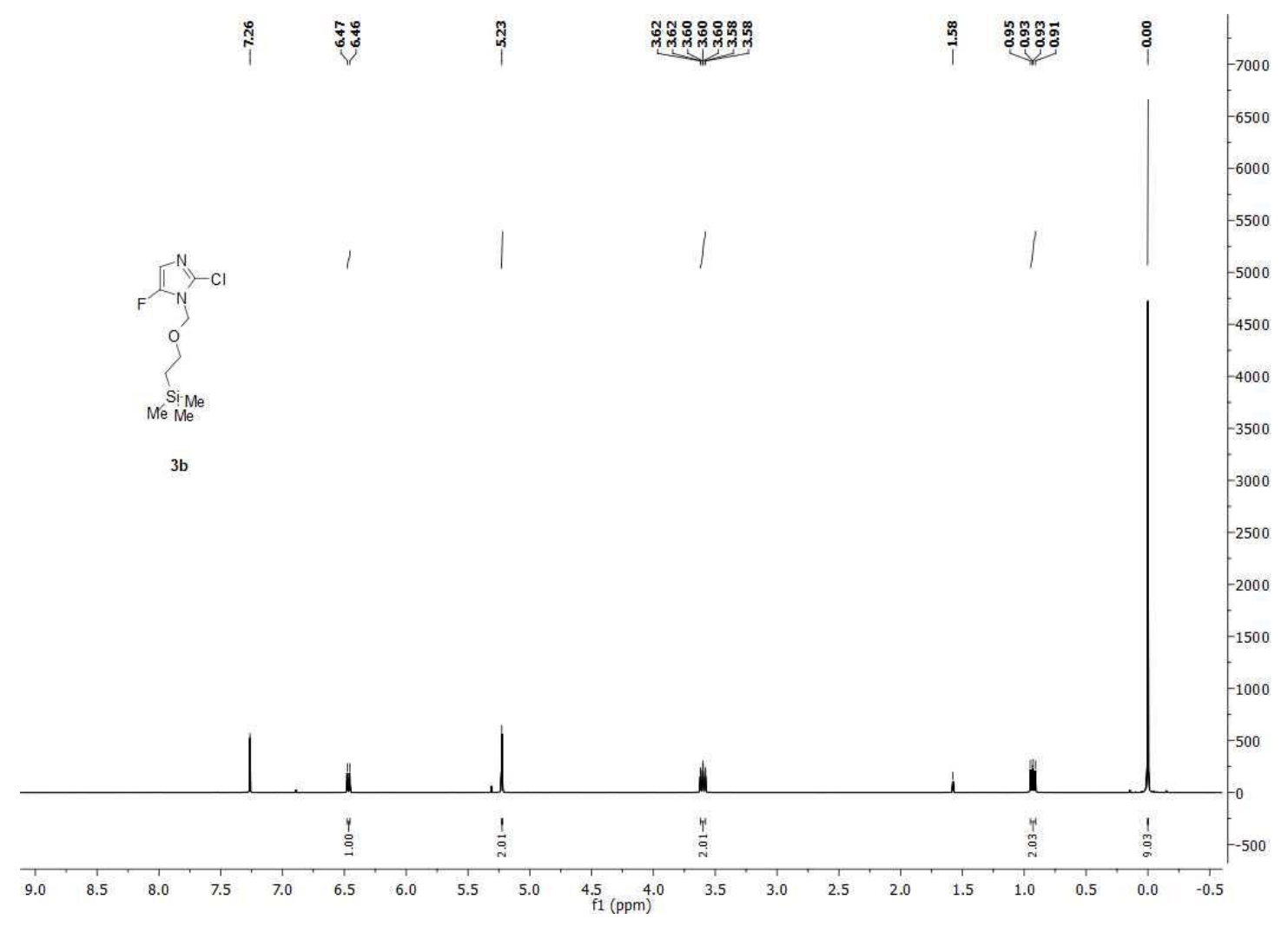




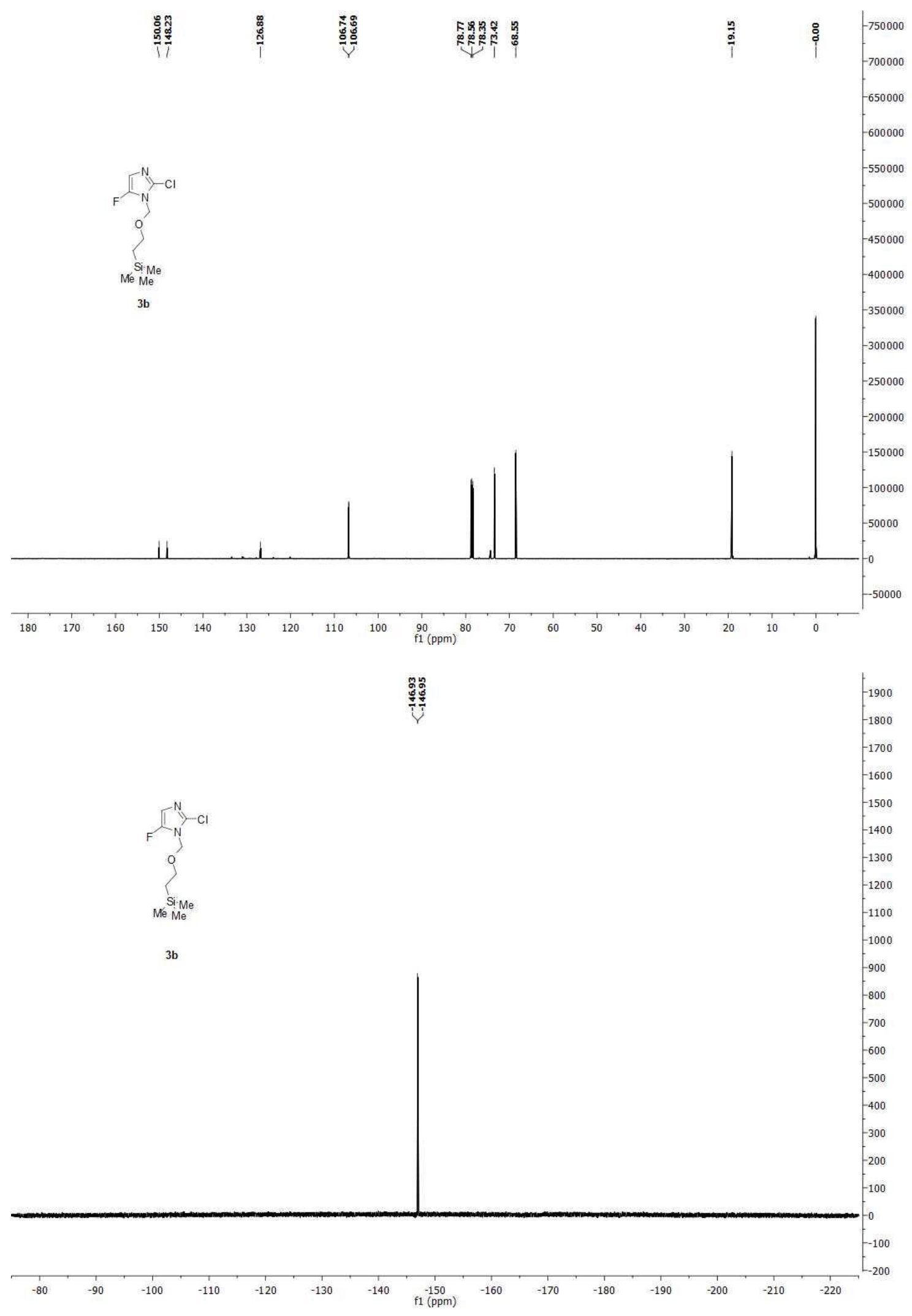


2-chloro-1-(1-ethoxyethyl)-5-fluoro-1 $H$-imidazole (3c).

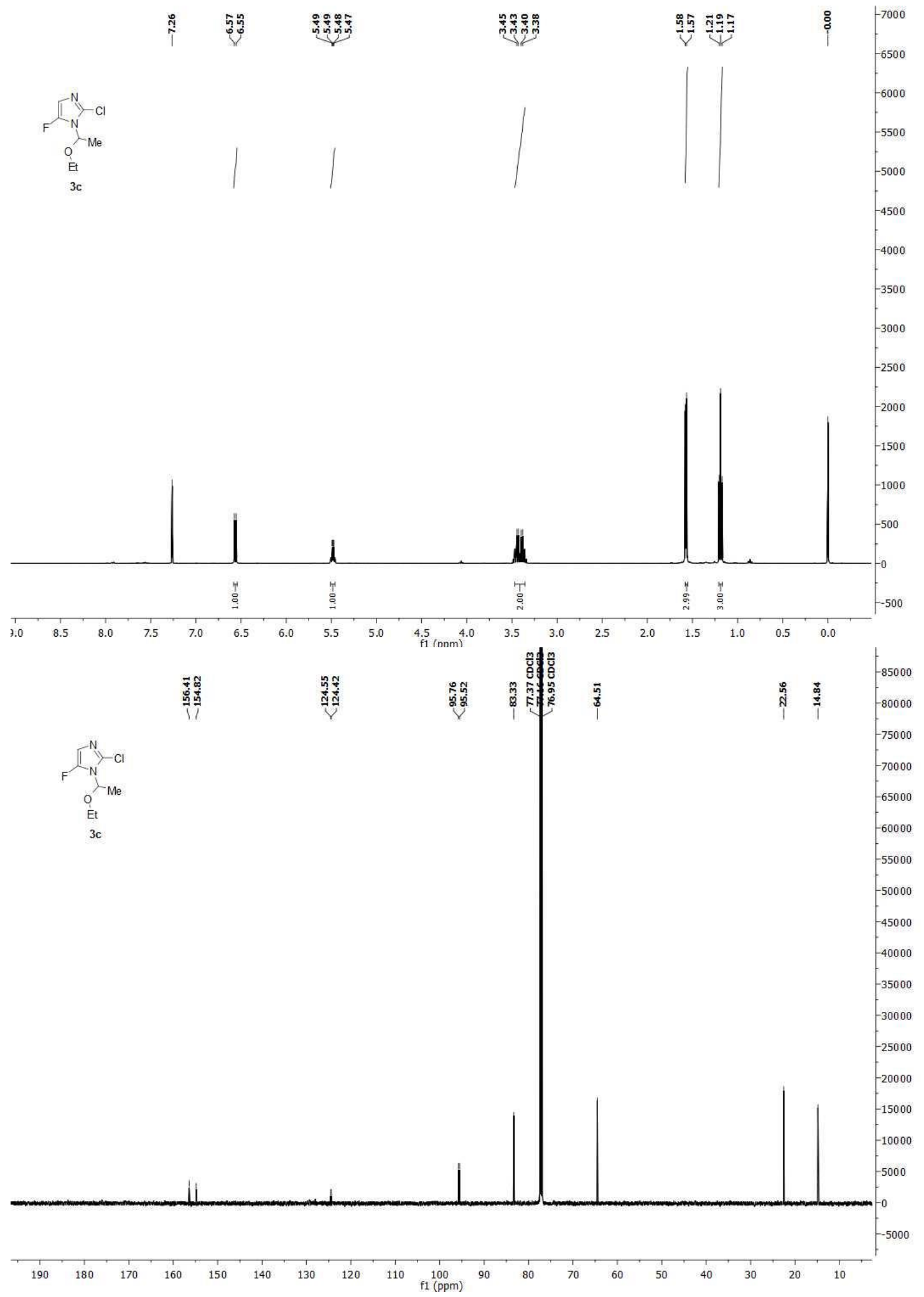




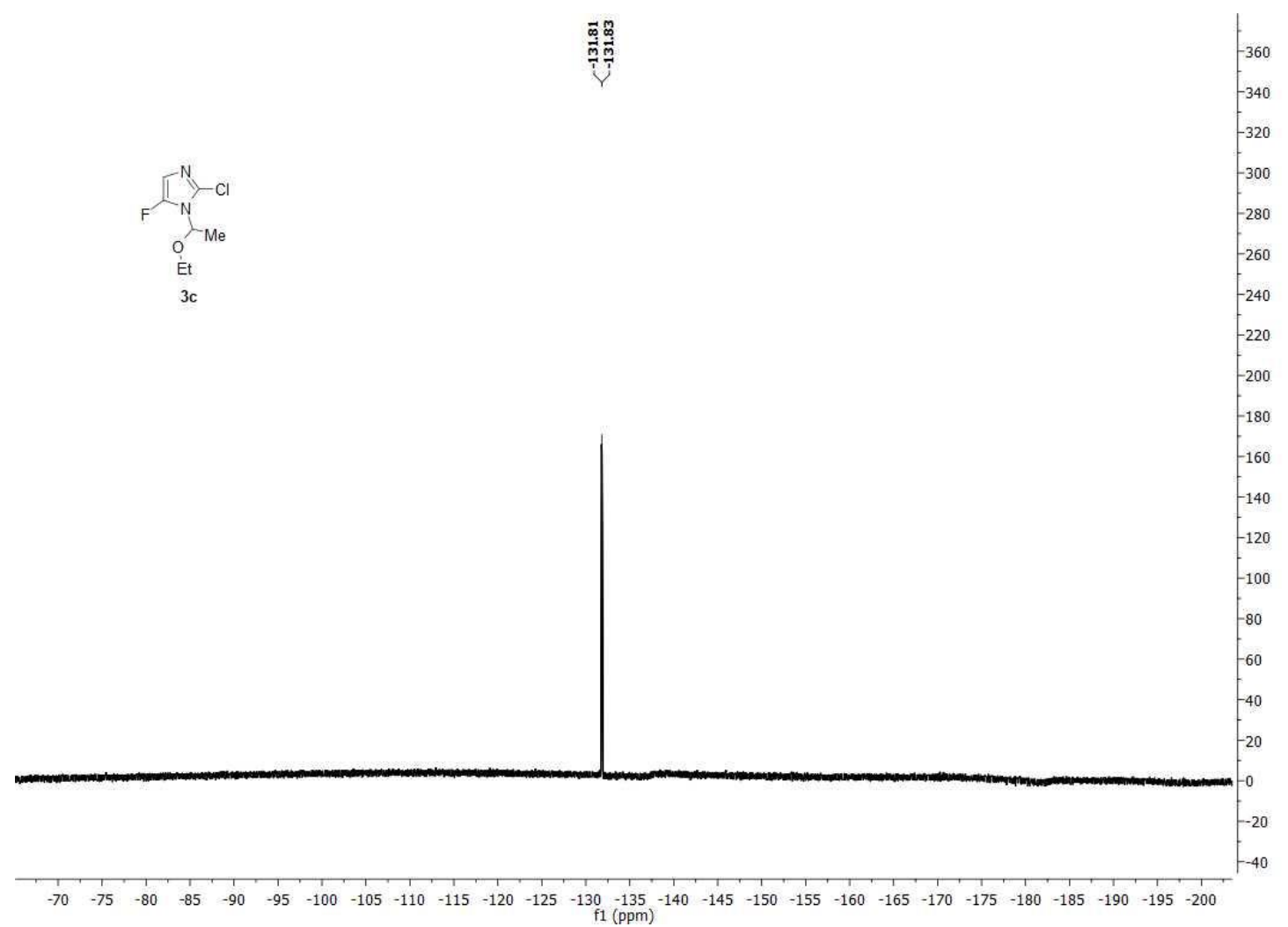

2-chloro-5-fluoro- $N, N$-dimethyl-1 $H$-imidazole-1-sulfonamide (3d).

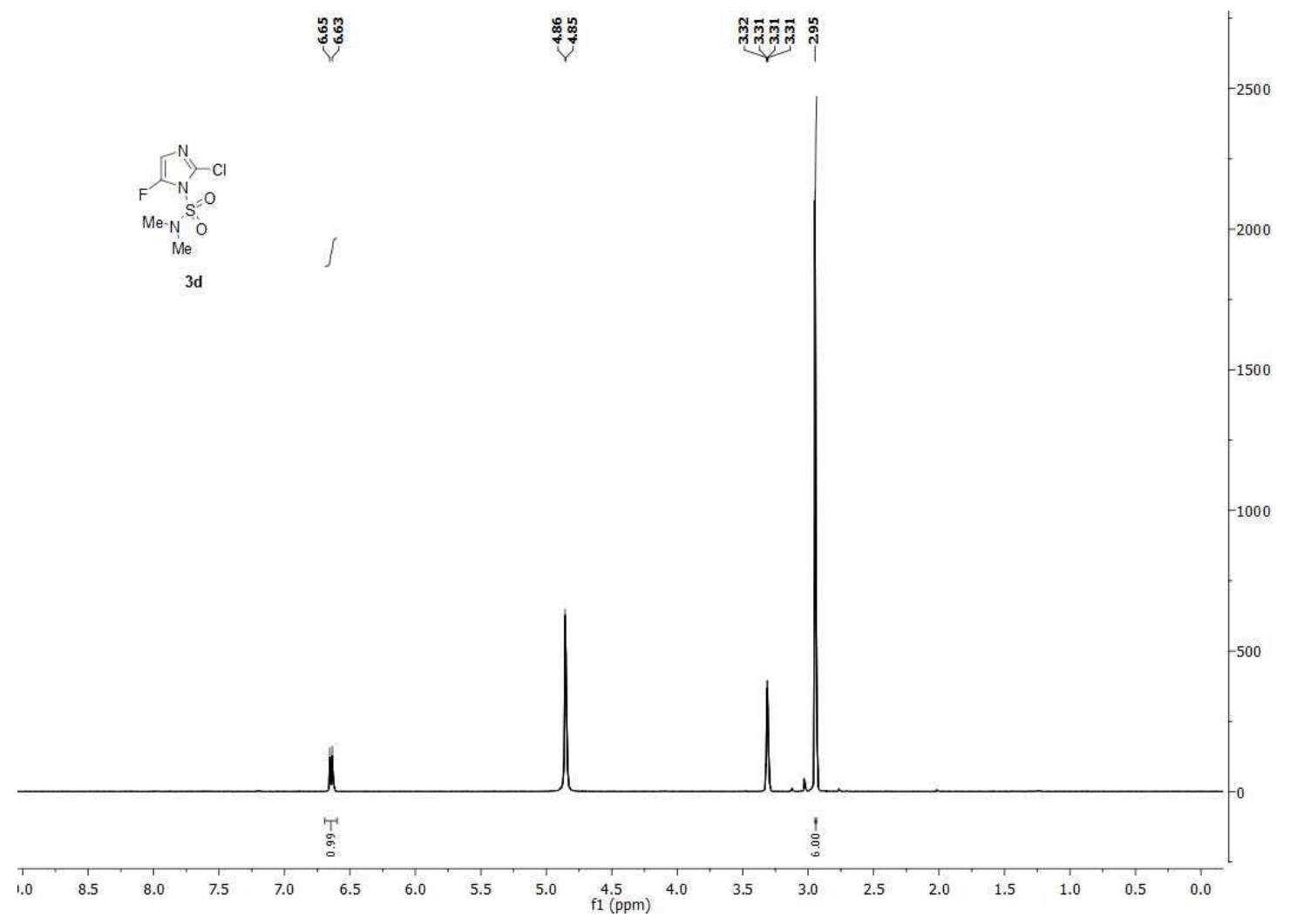




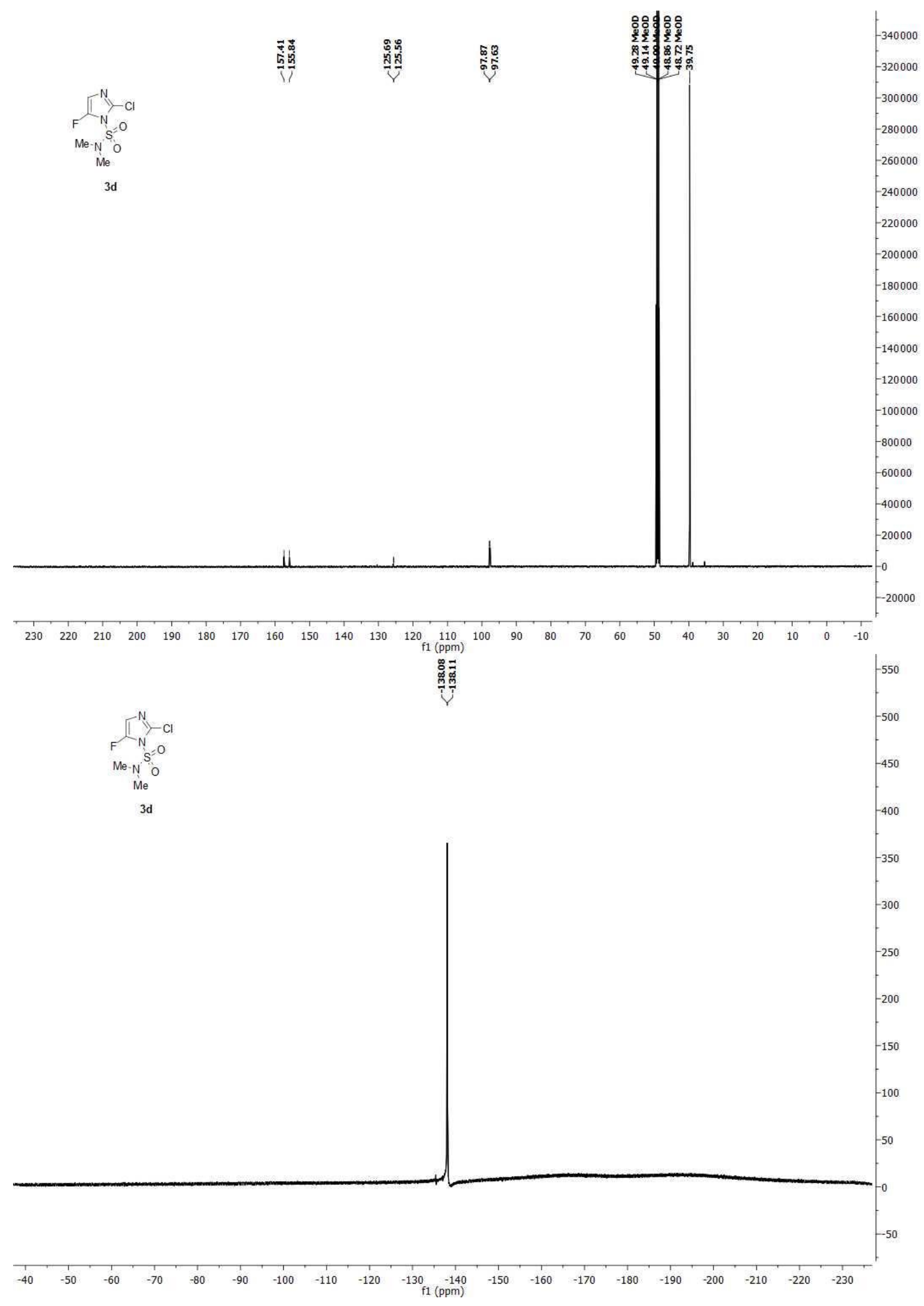


2-chloro-1-(ethoxymethyl)-5-fluoro-4-methyl-1 $\mathrm{H}$-imidazole (5a).

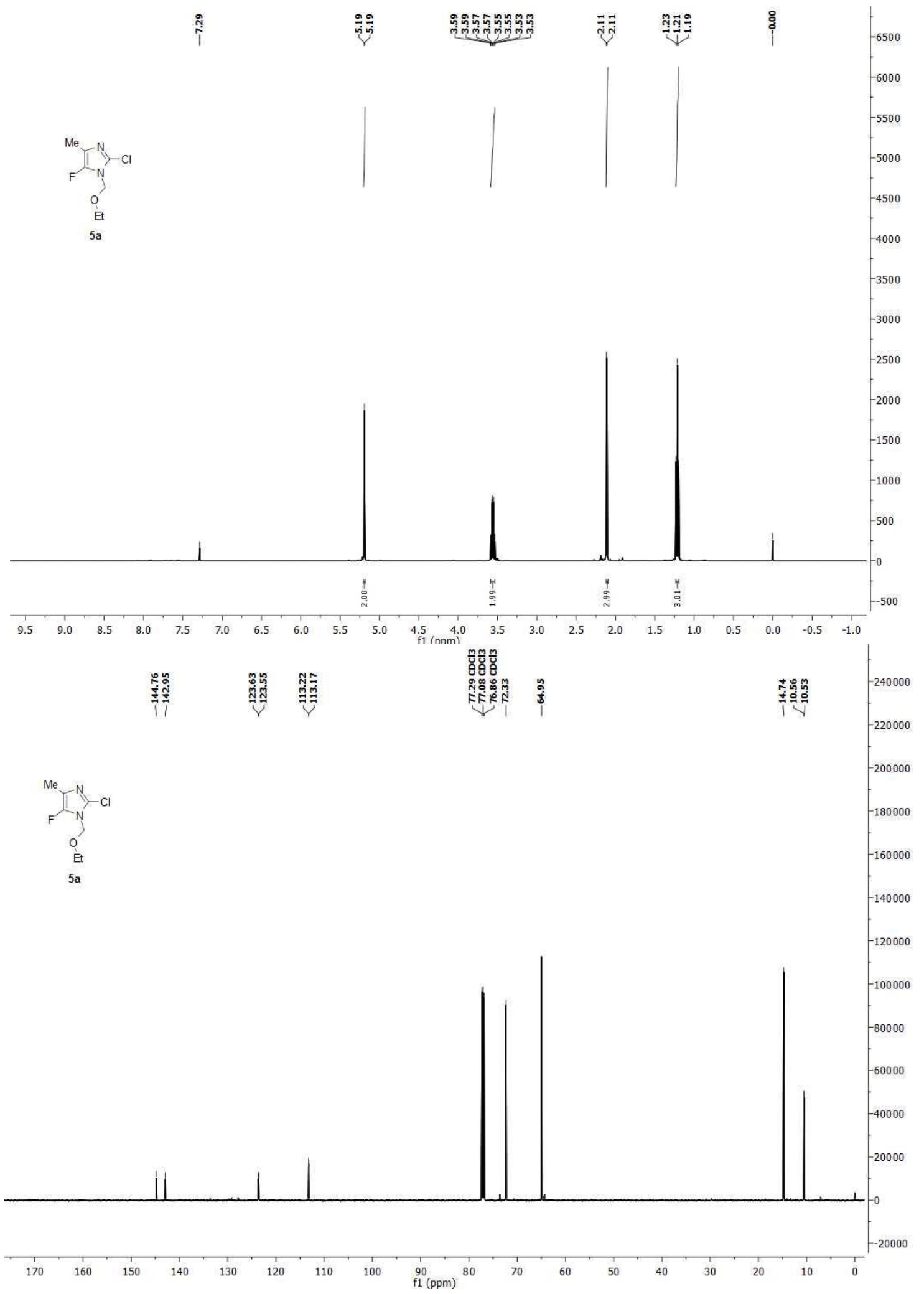




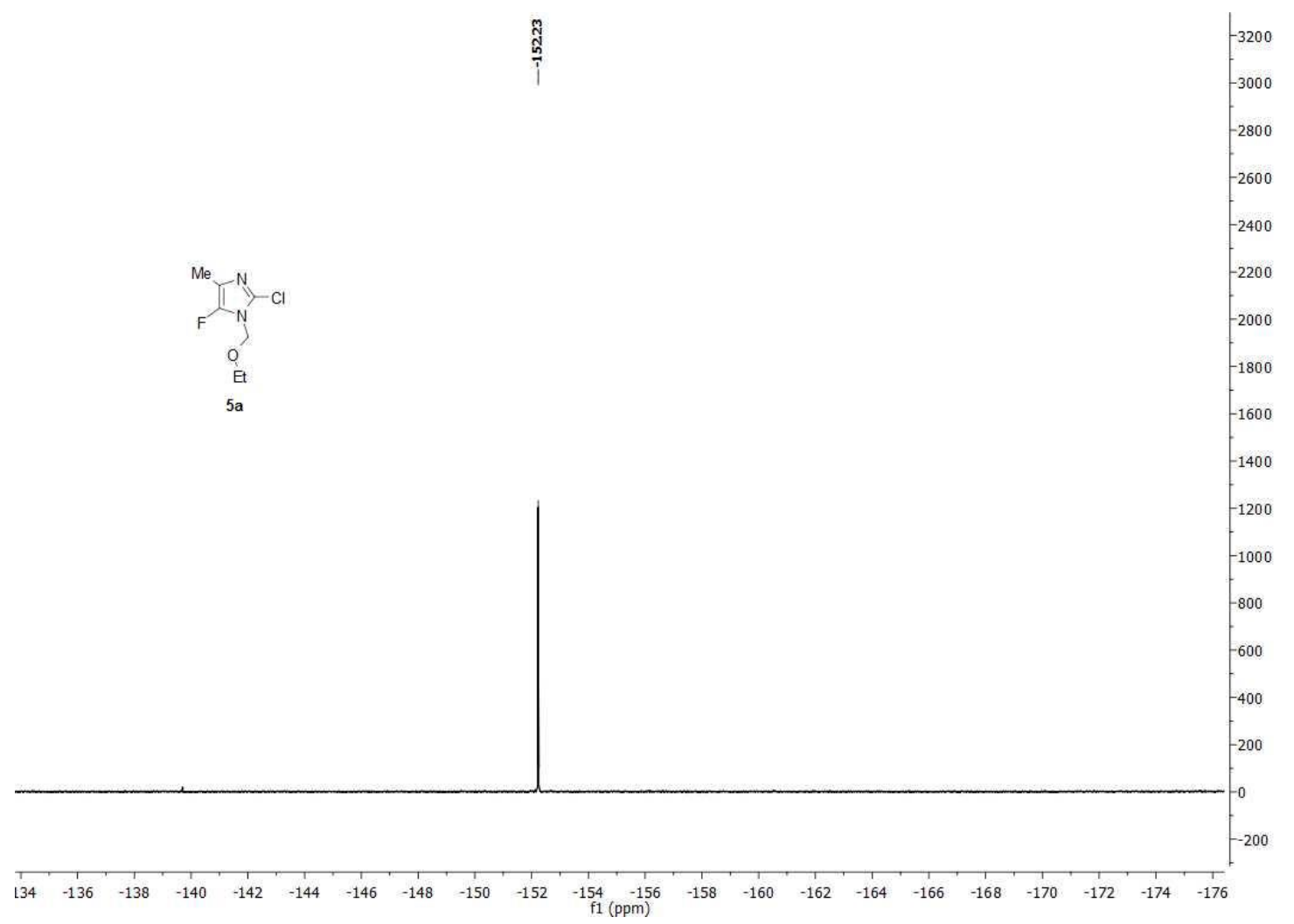

2-chloro-1-(ethoxymethyl)-5-fluoro-4-phenyl-1H-imidazole (5b)

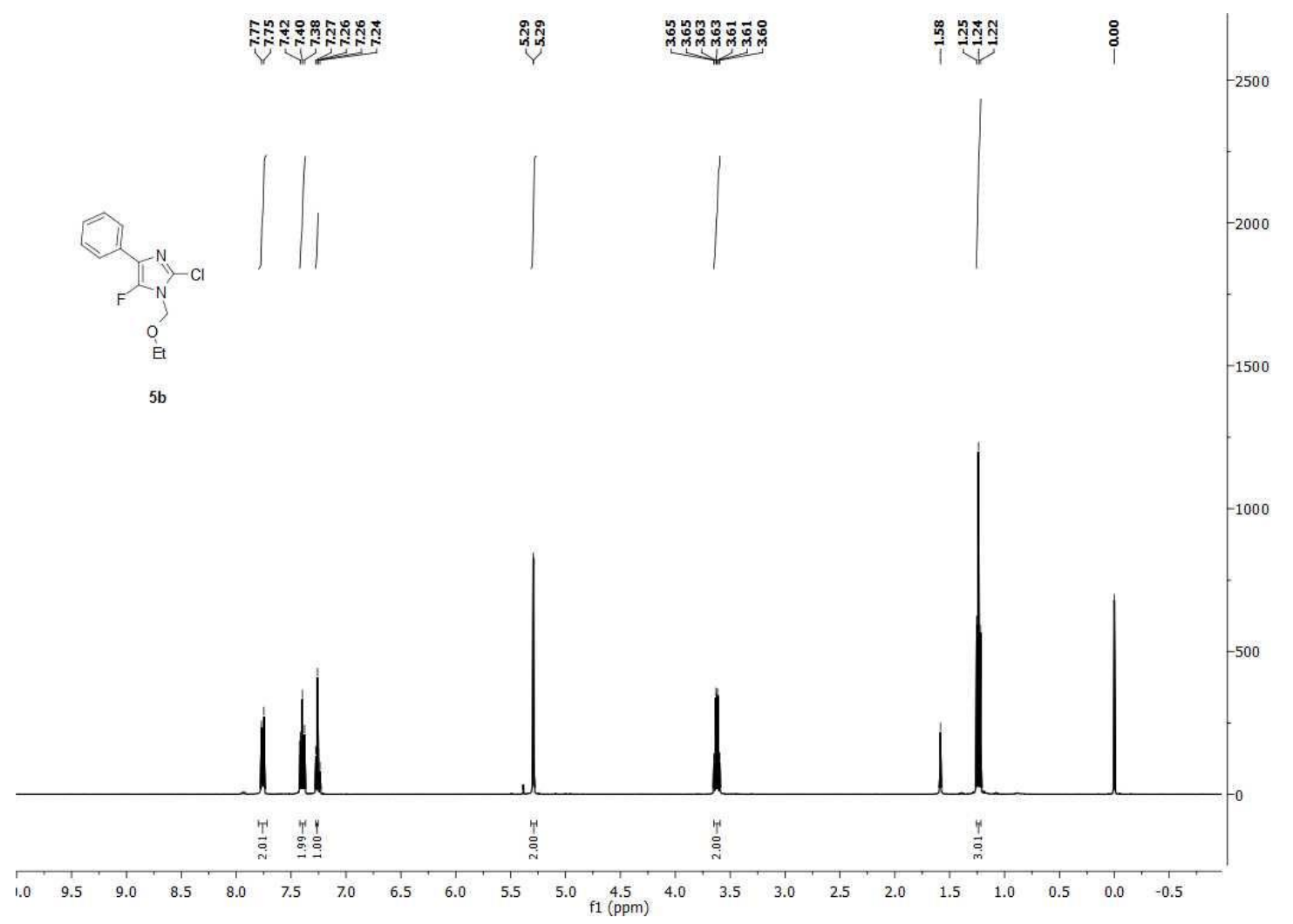




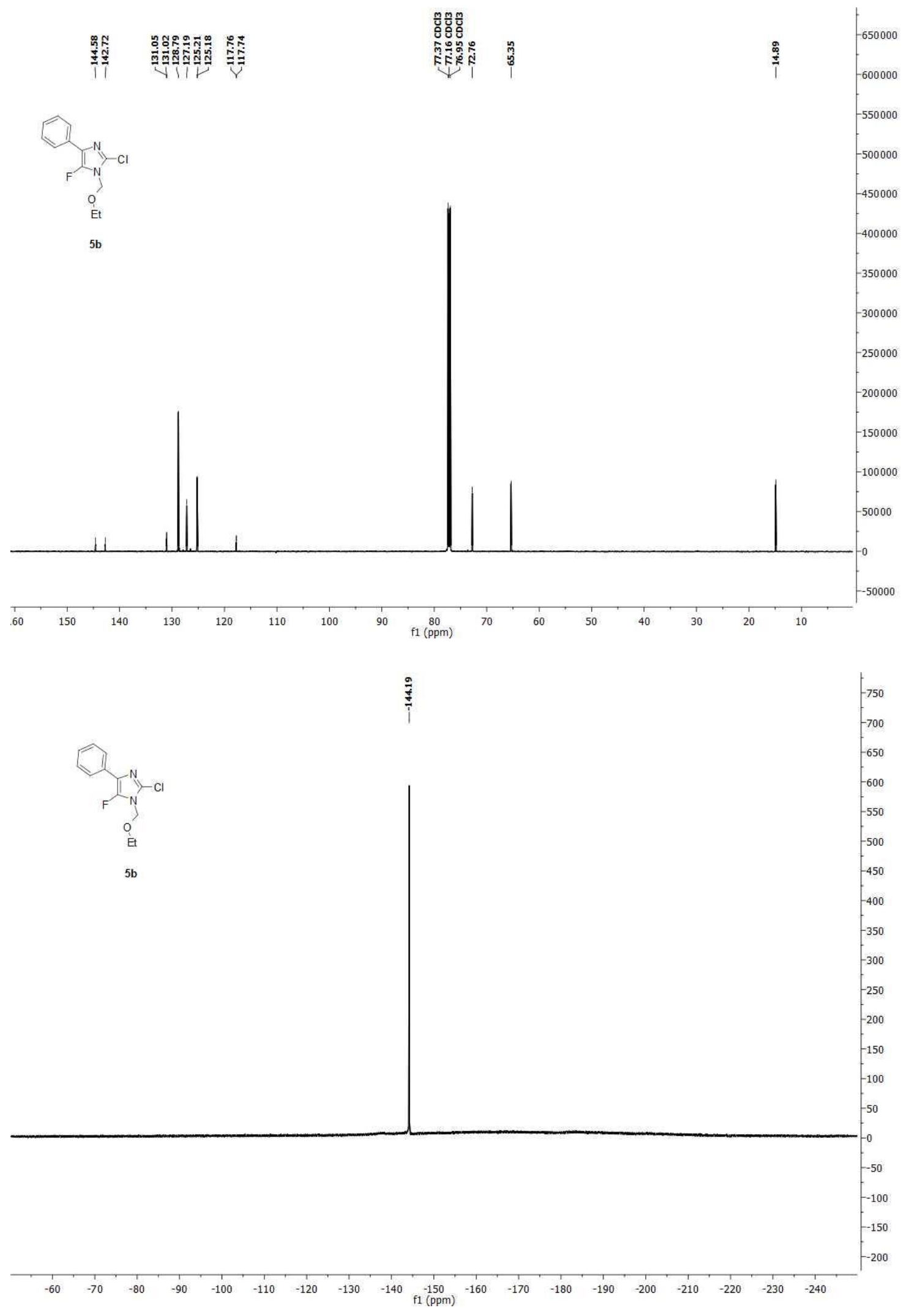


2-chloro-4-(4-chlorophenyl)-1-(ethoxymethyl)-5-fluoro-1 $H$-imidazole (5c).

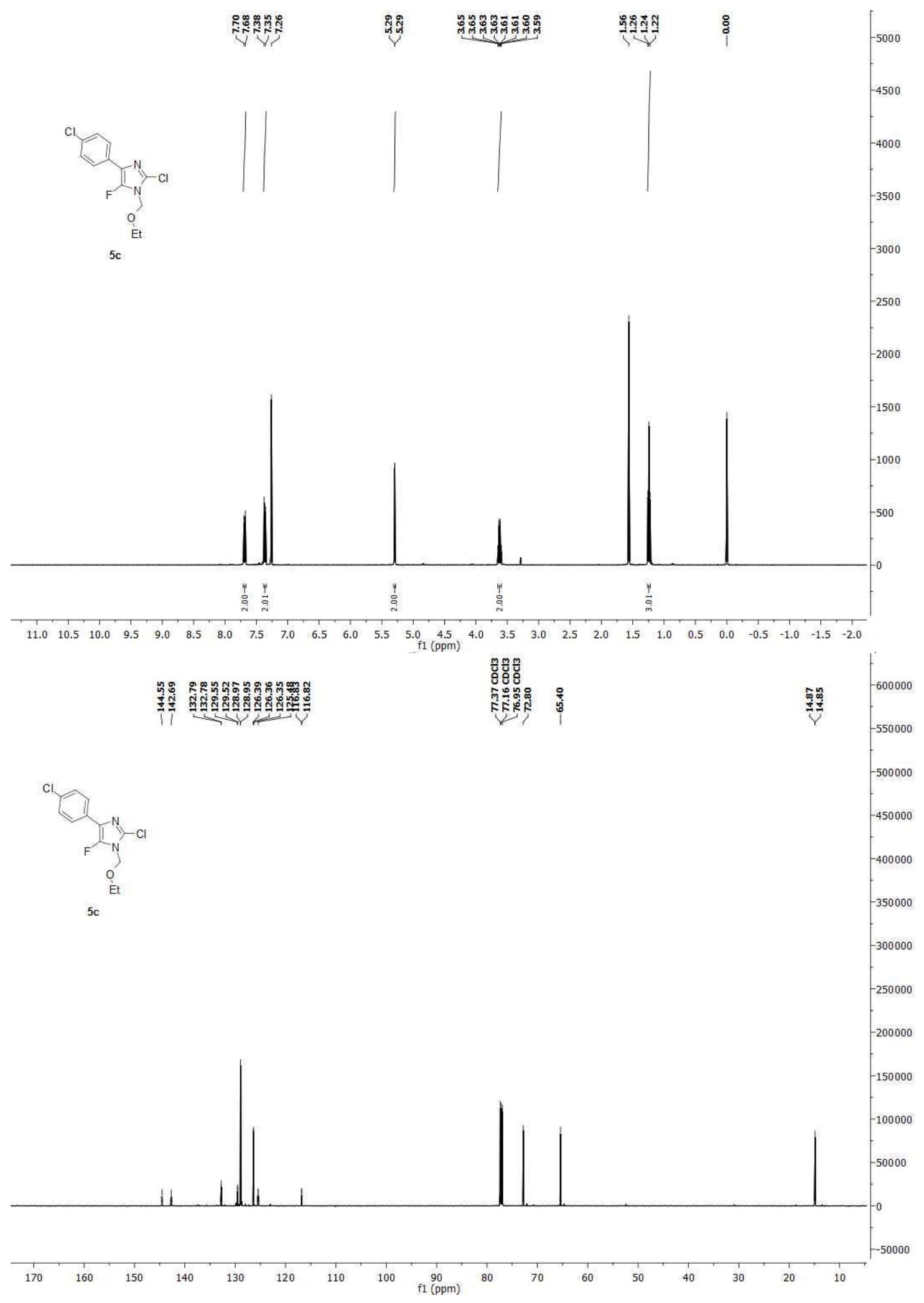




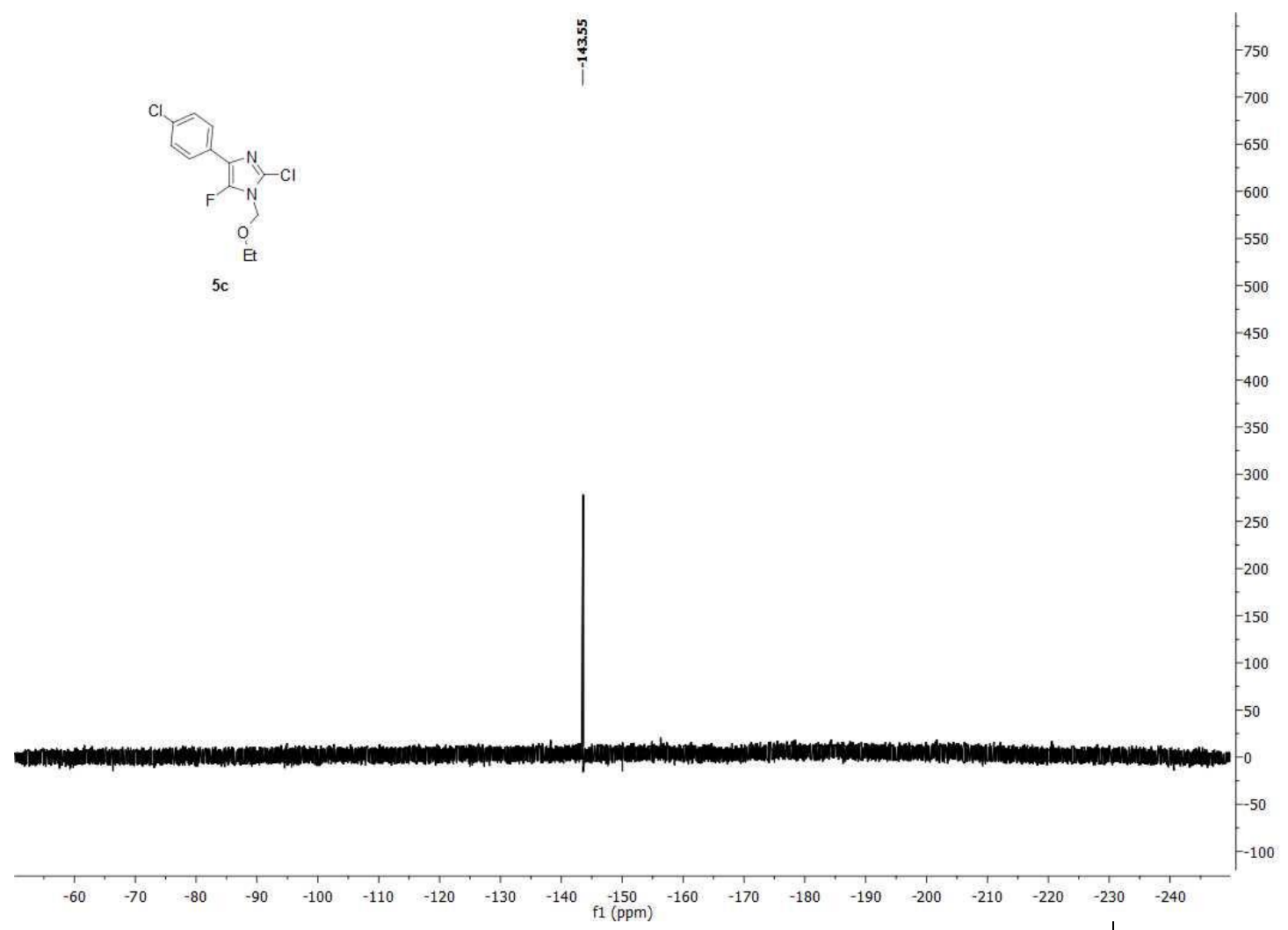

2-chloro-1-(ethoxymethyl)-5-fluoro-4-(4-fluorophenyl)-1 $\mathrm{H}$-imidazole (5d)

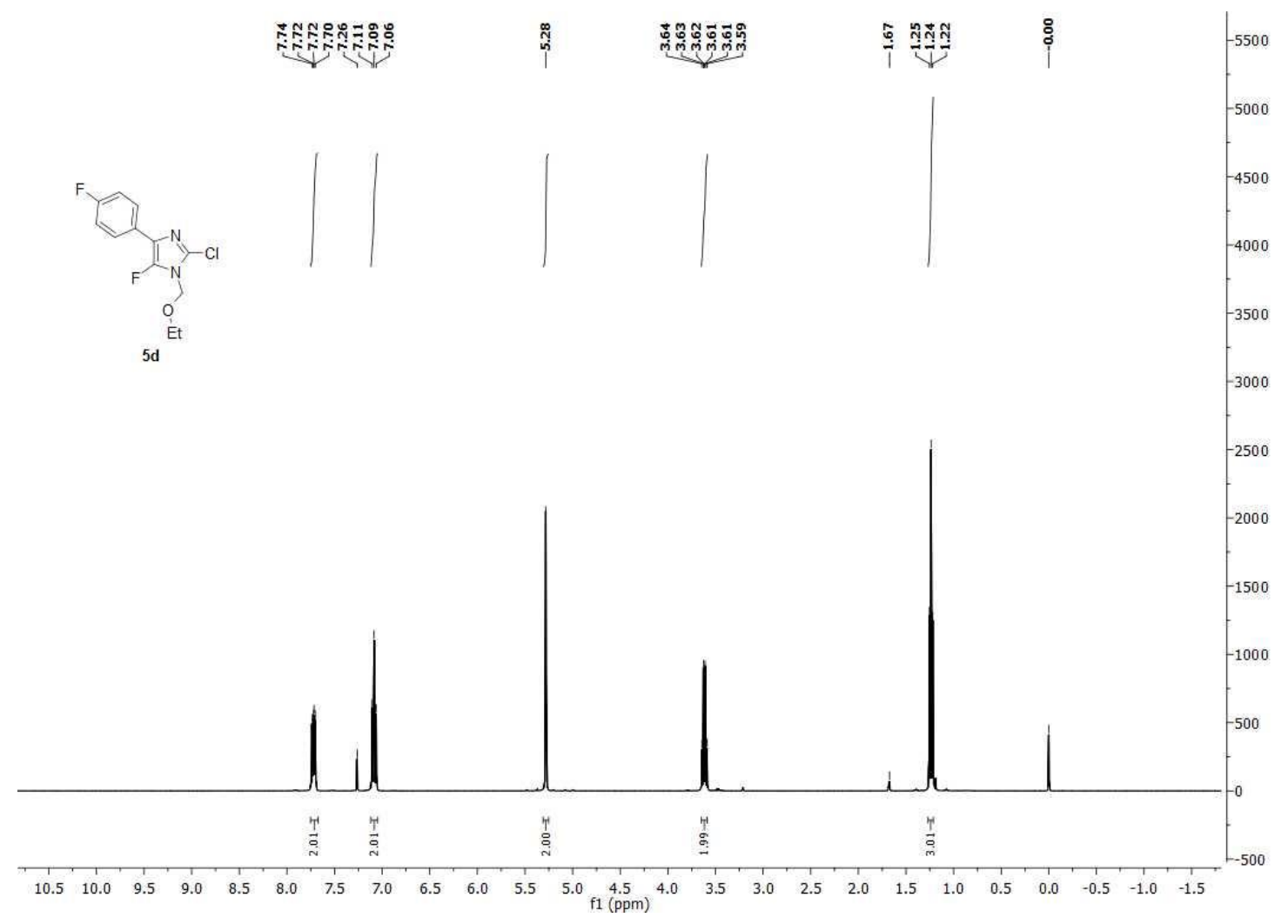




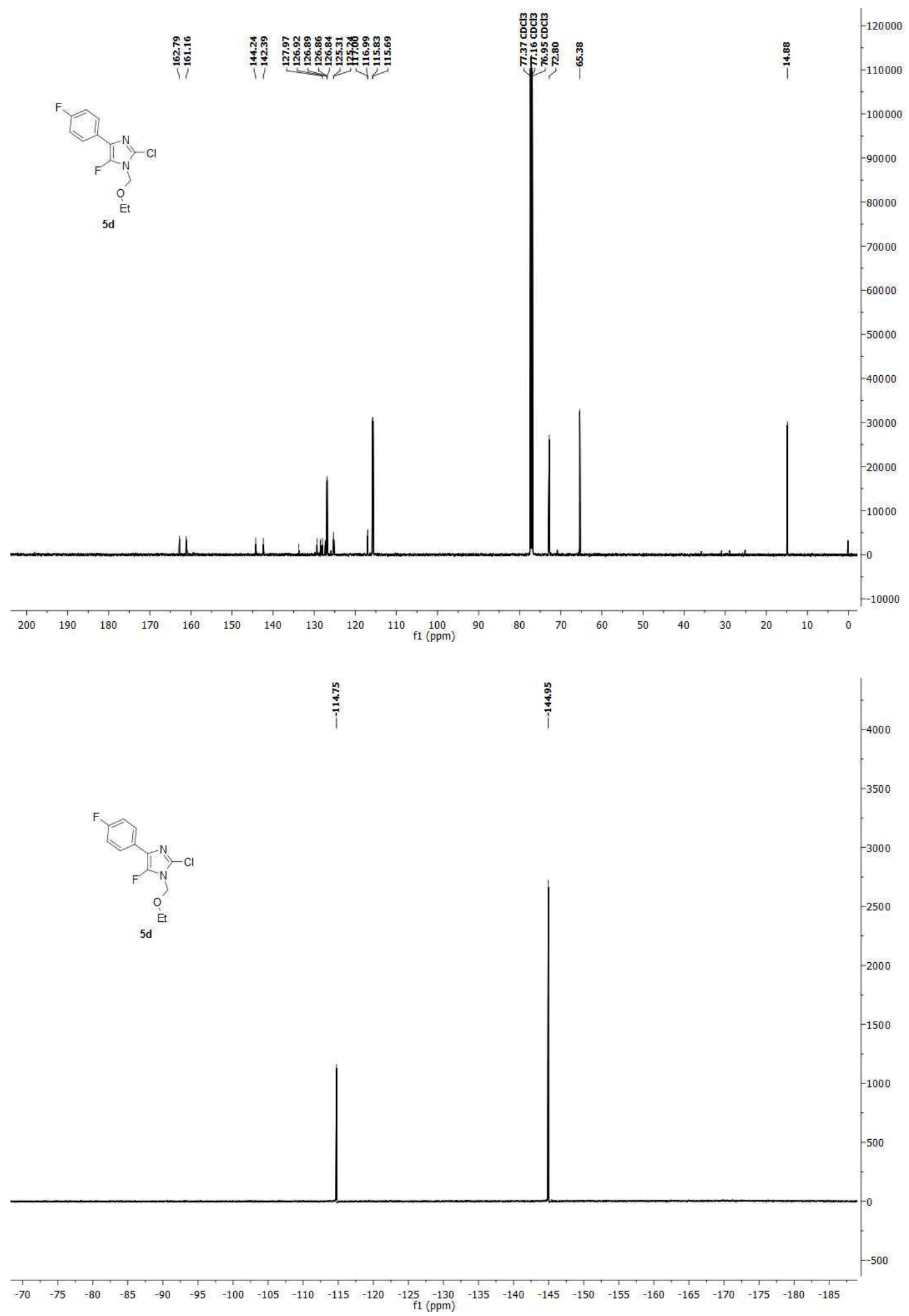


1-(ethoxymethyl)-5-fluoro-2-phenyl-1 $H$-imidazole (5e).

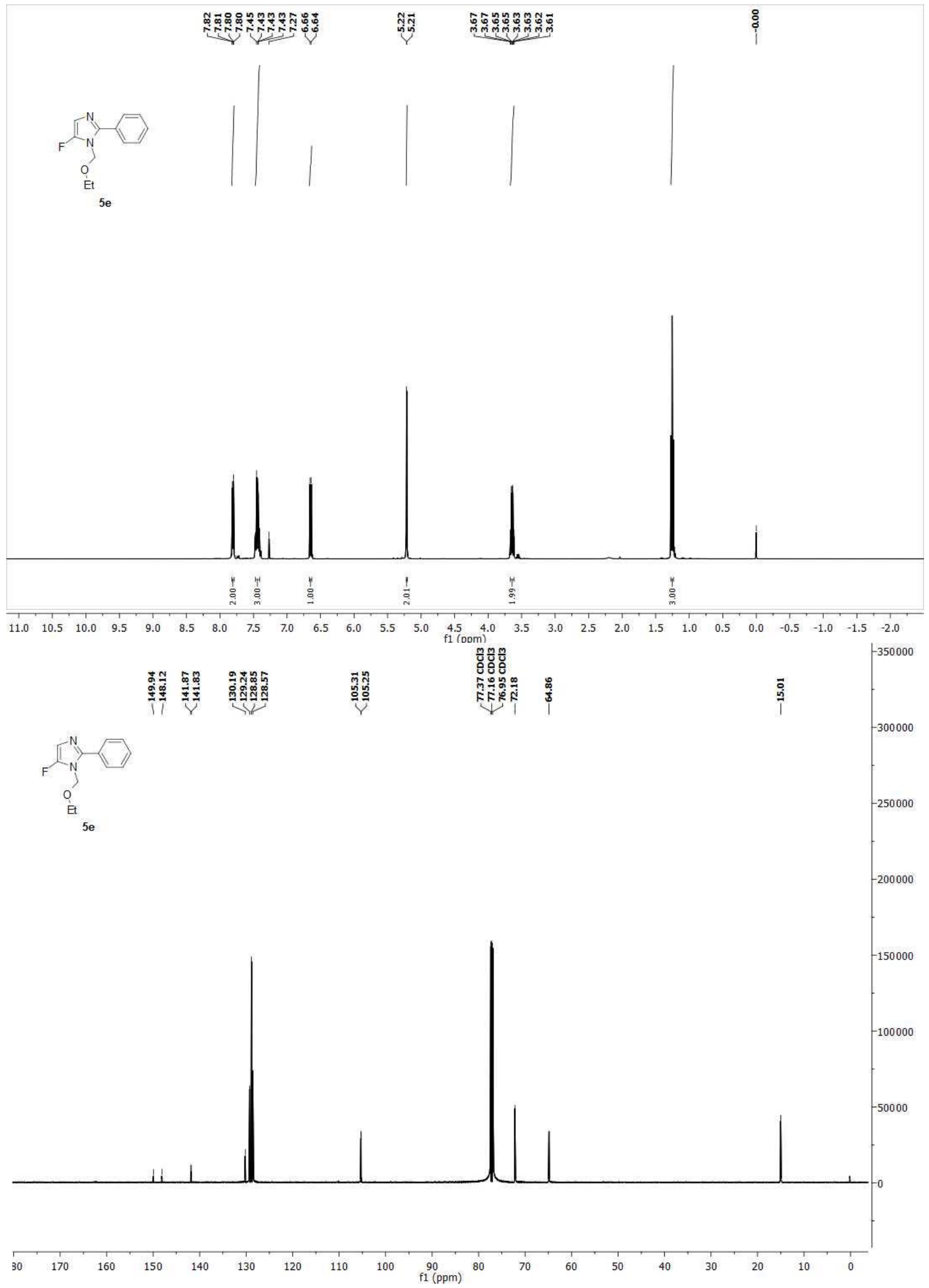




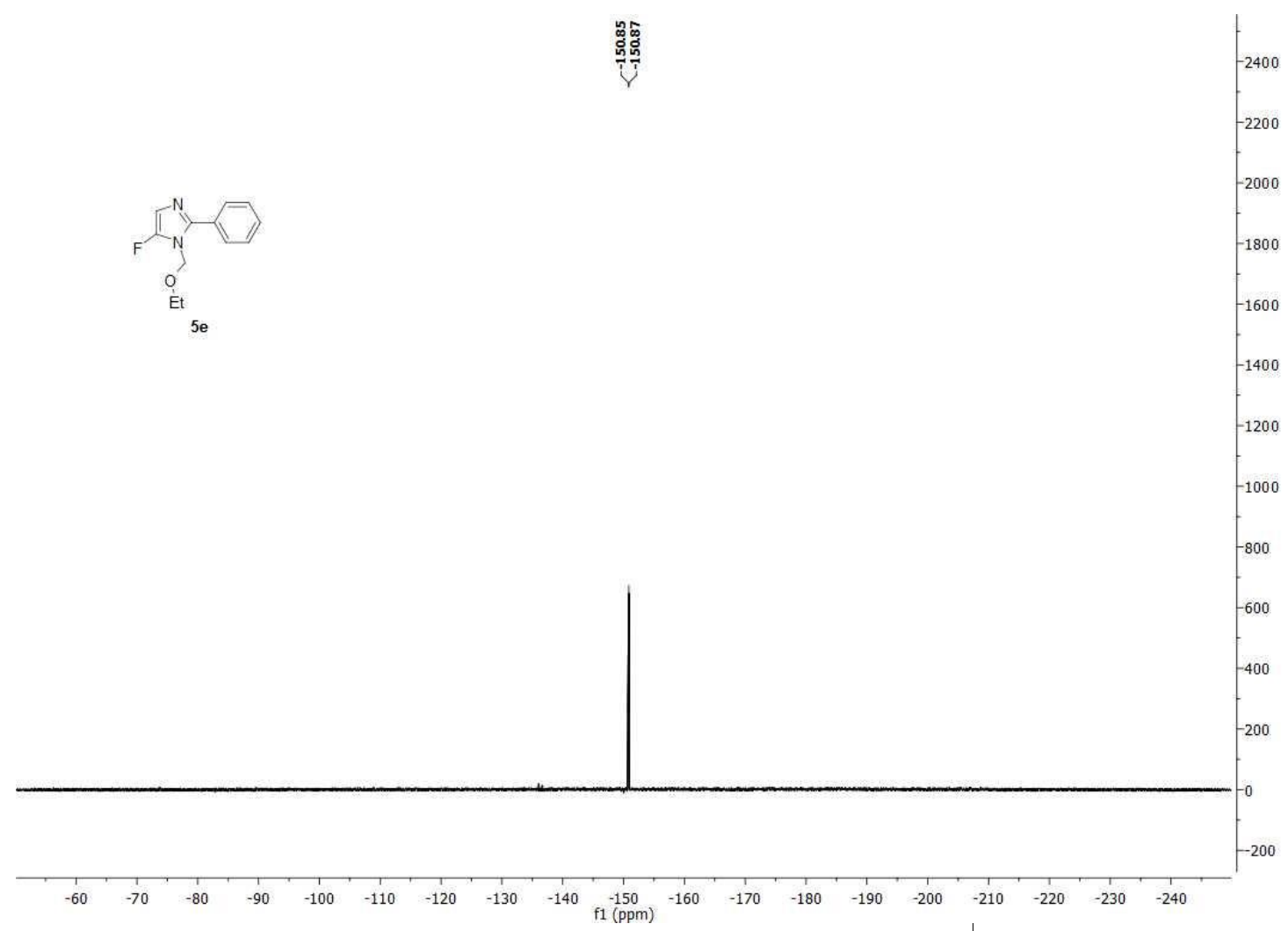

2-(4-chlorophenyl)-1-(ethoxymethyl)-5-fluoro-1 $H$-imidazole (5f)

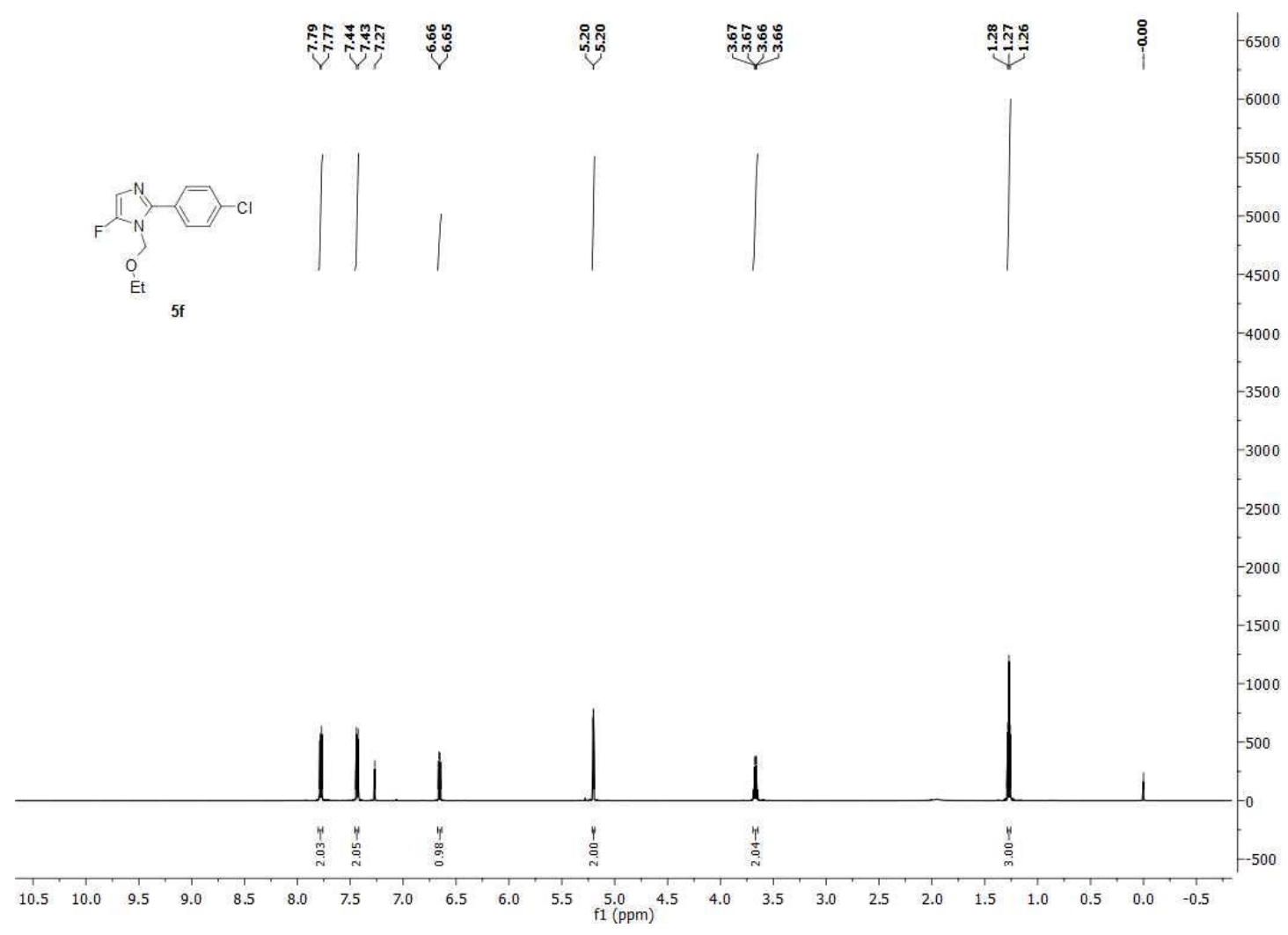




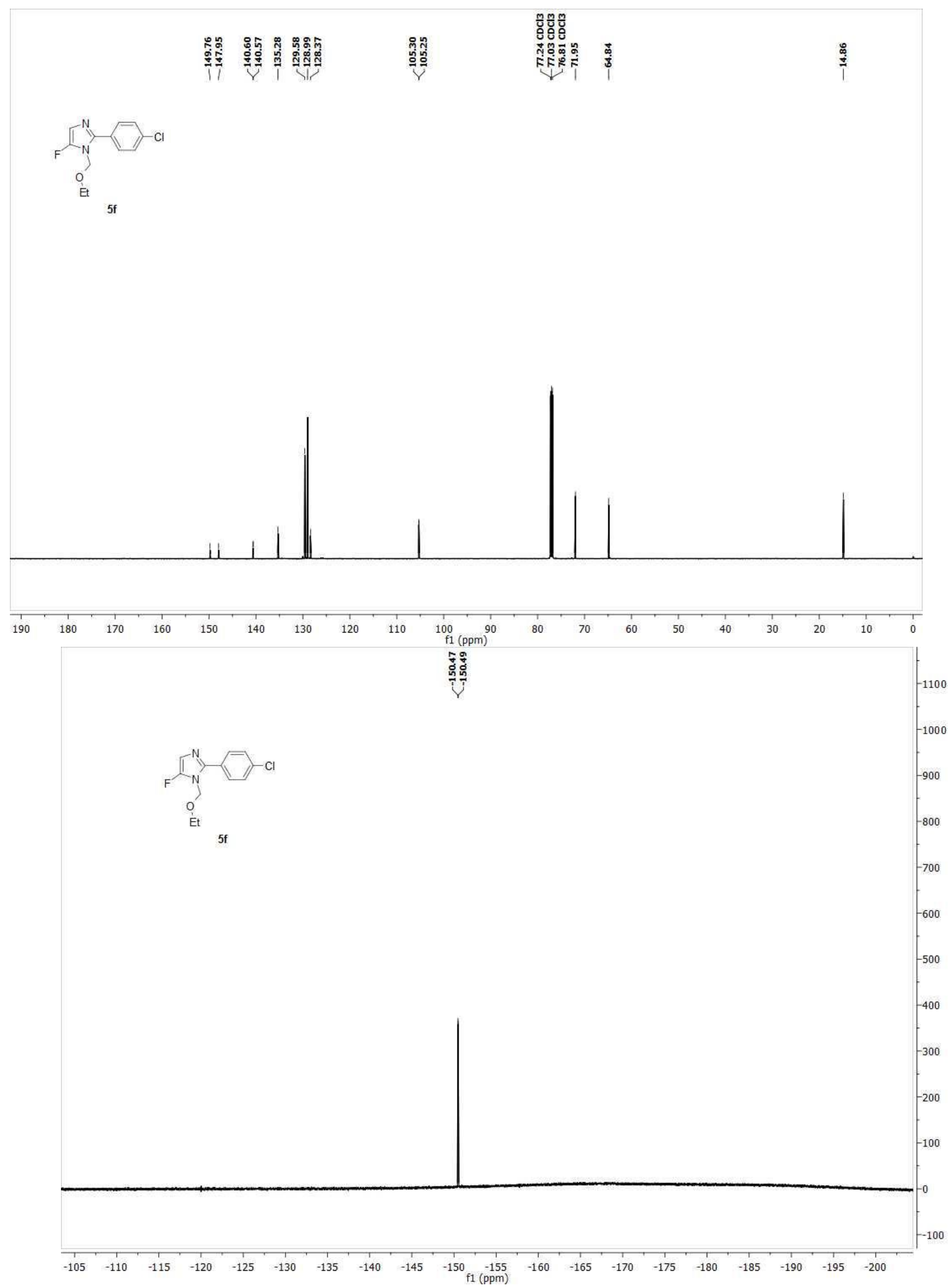


1-(ethoxymethyl)-5-fluoro-2-(4-fluorophenyl)-1 $H$-imidazole (5g).

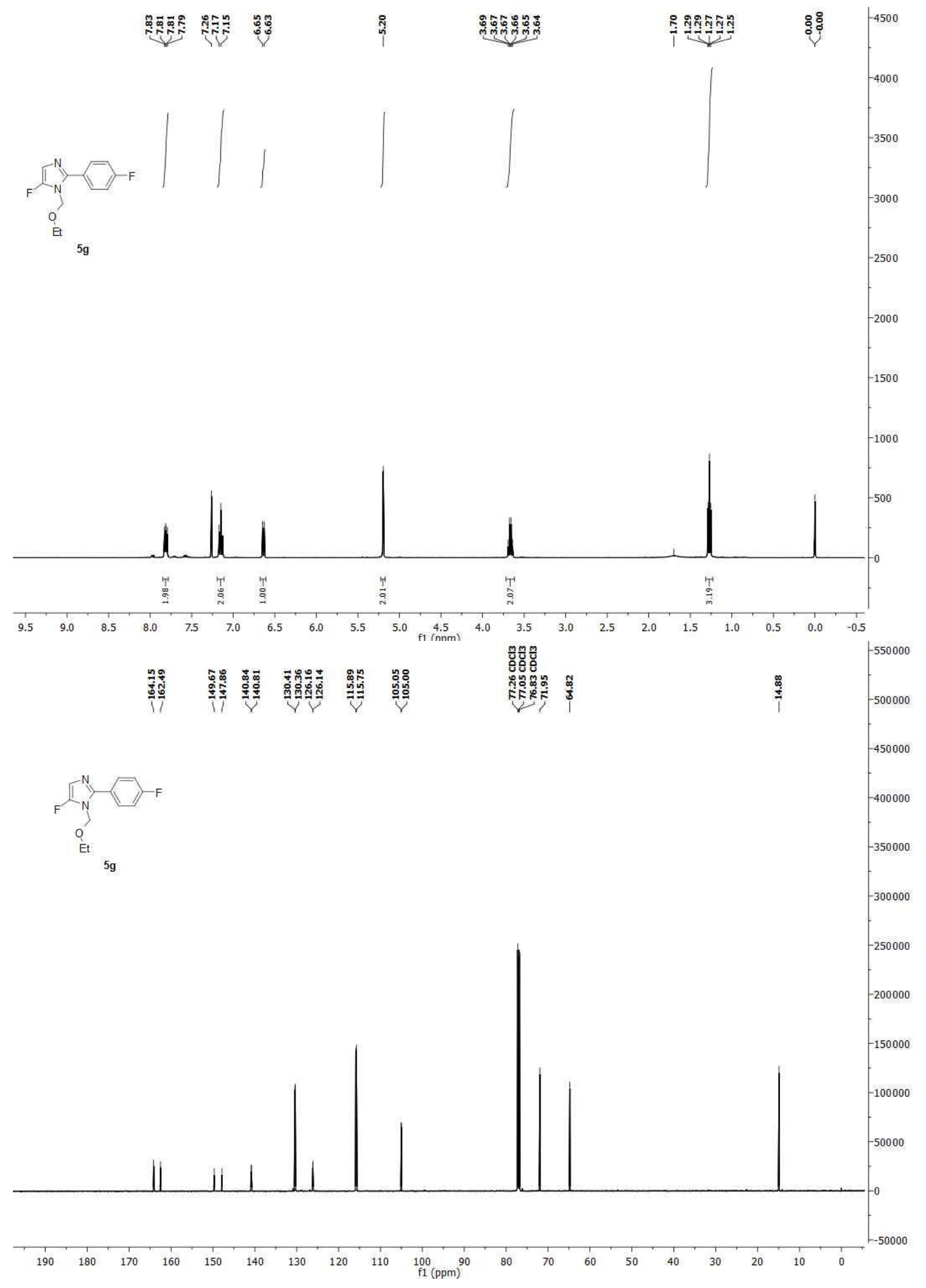




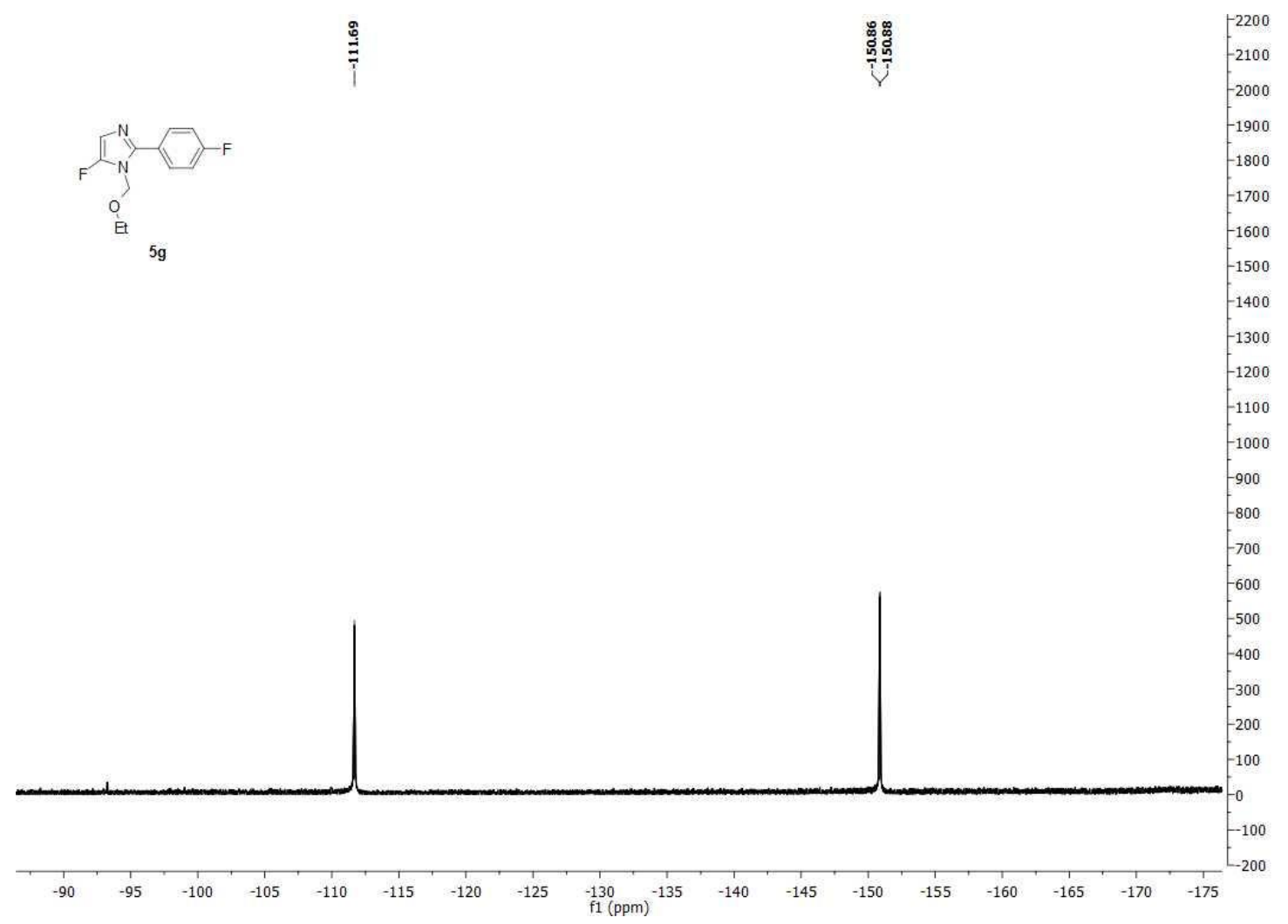

2-chloro-1-(ethoxymethyl)-4-fluoro-1 $\mathrm{H}$-imidazole (6a).

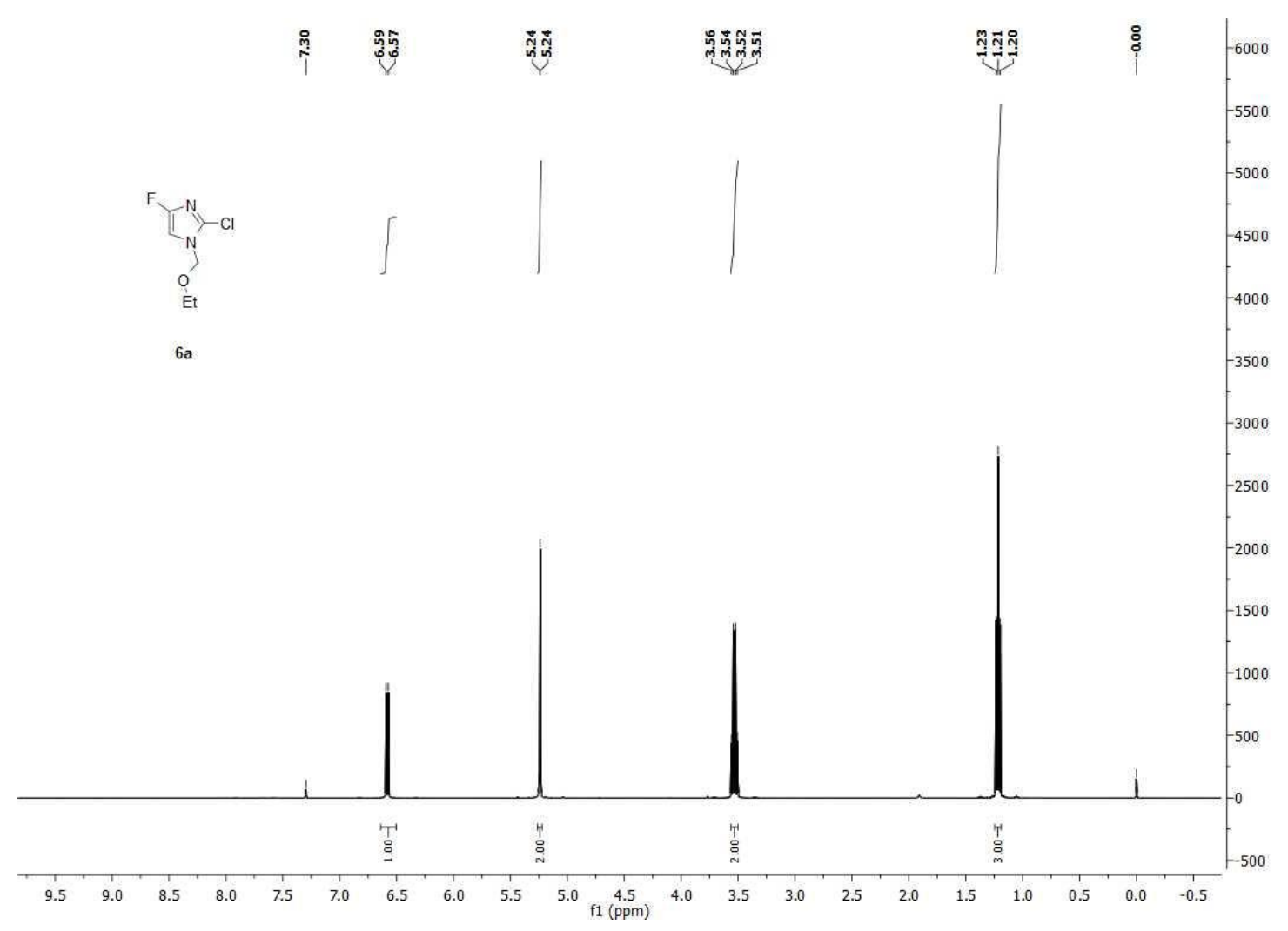




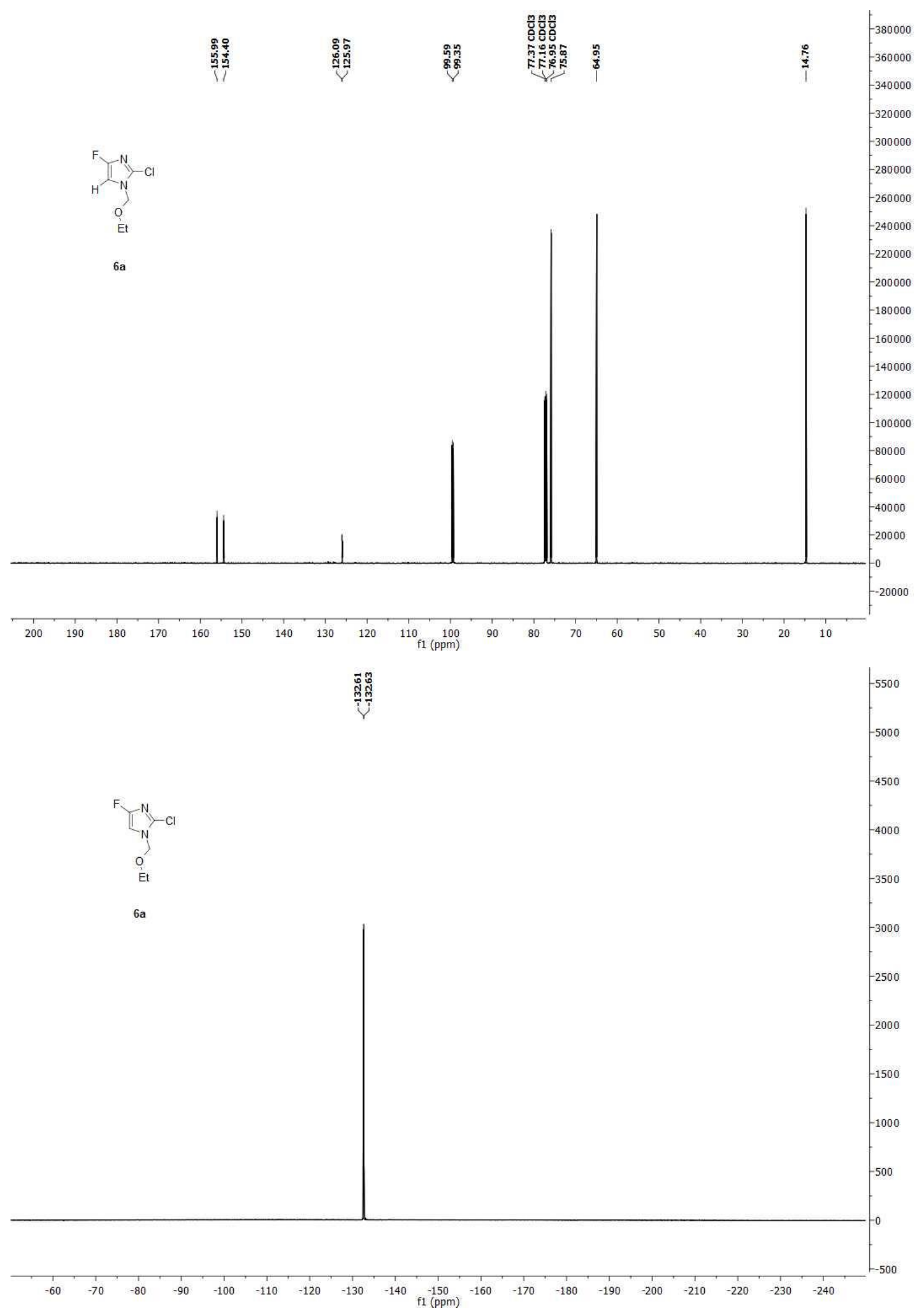


2-chloro-5-(4-chlorophenyl)-1-(ethoxymethyl)-4-fluoro-1 $H$-imidazole (6b).

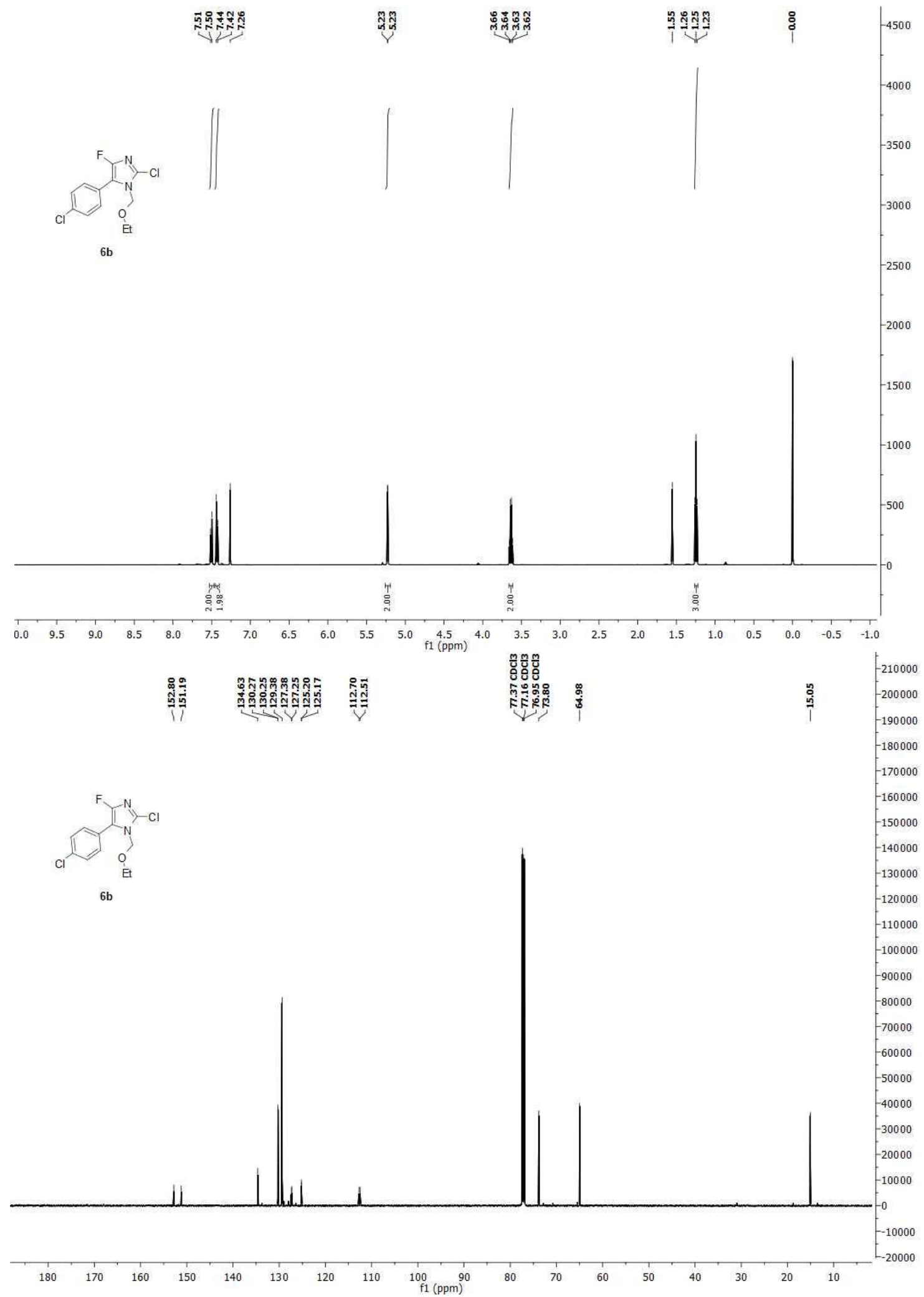




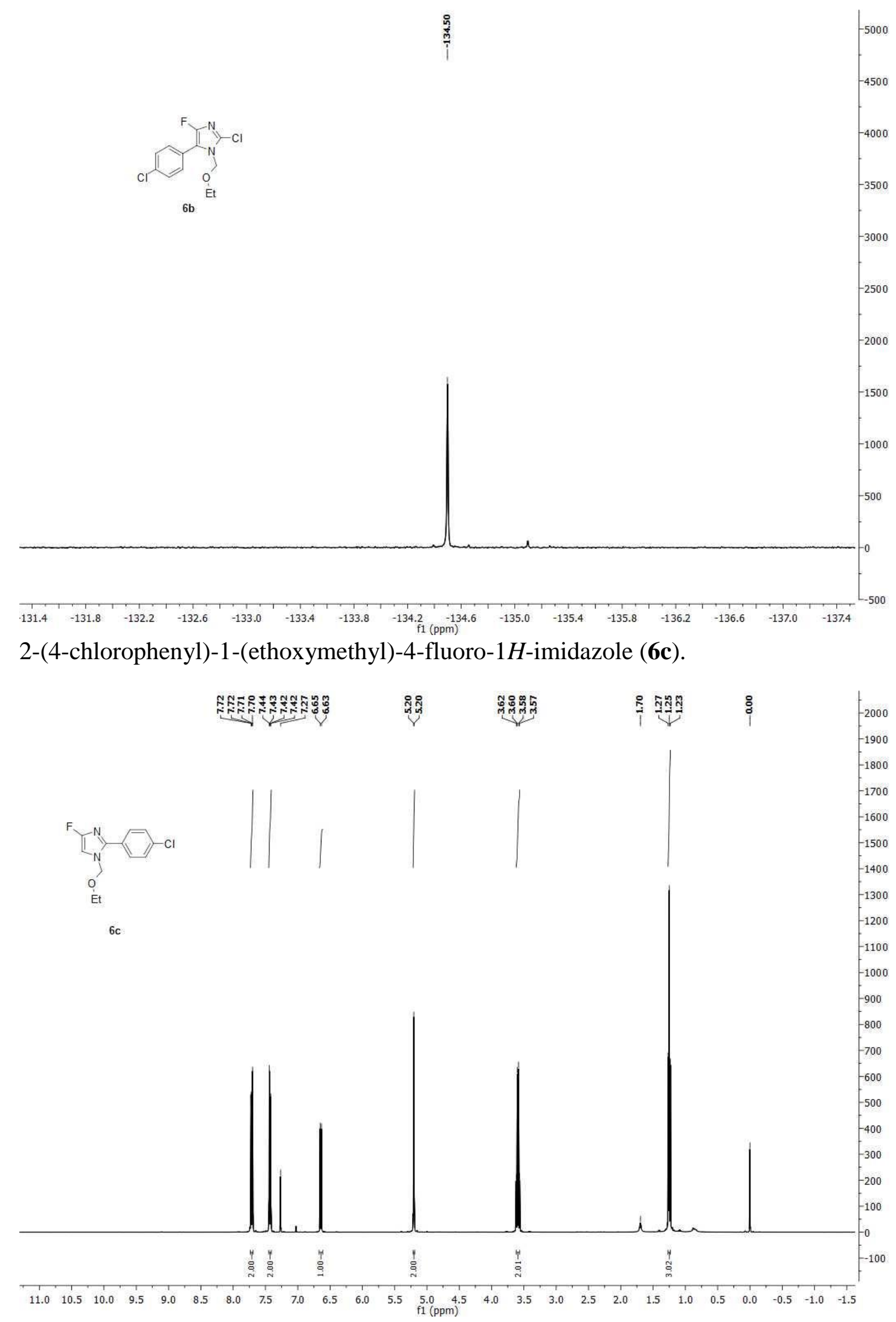




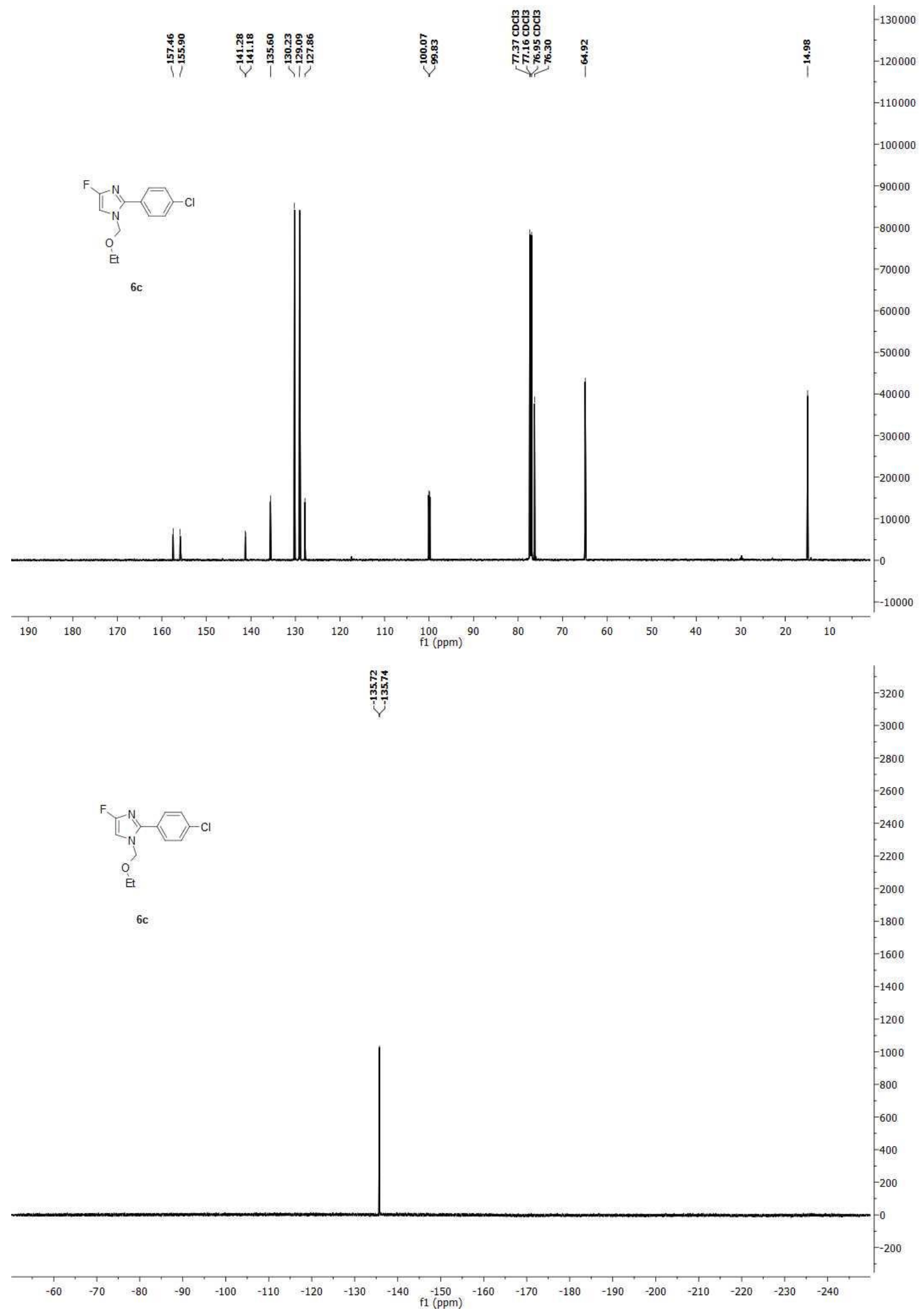


1-(ethoxymethyl)-4-fluoro-2-(4-fluorophenyl)-1 $\mathrm{H}$-imidazole (6d).

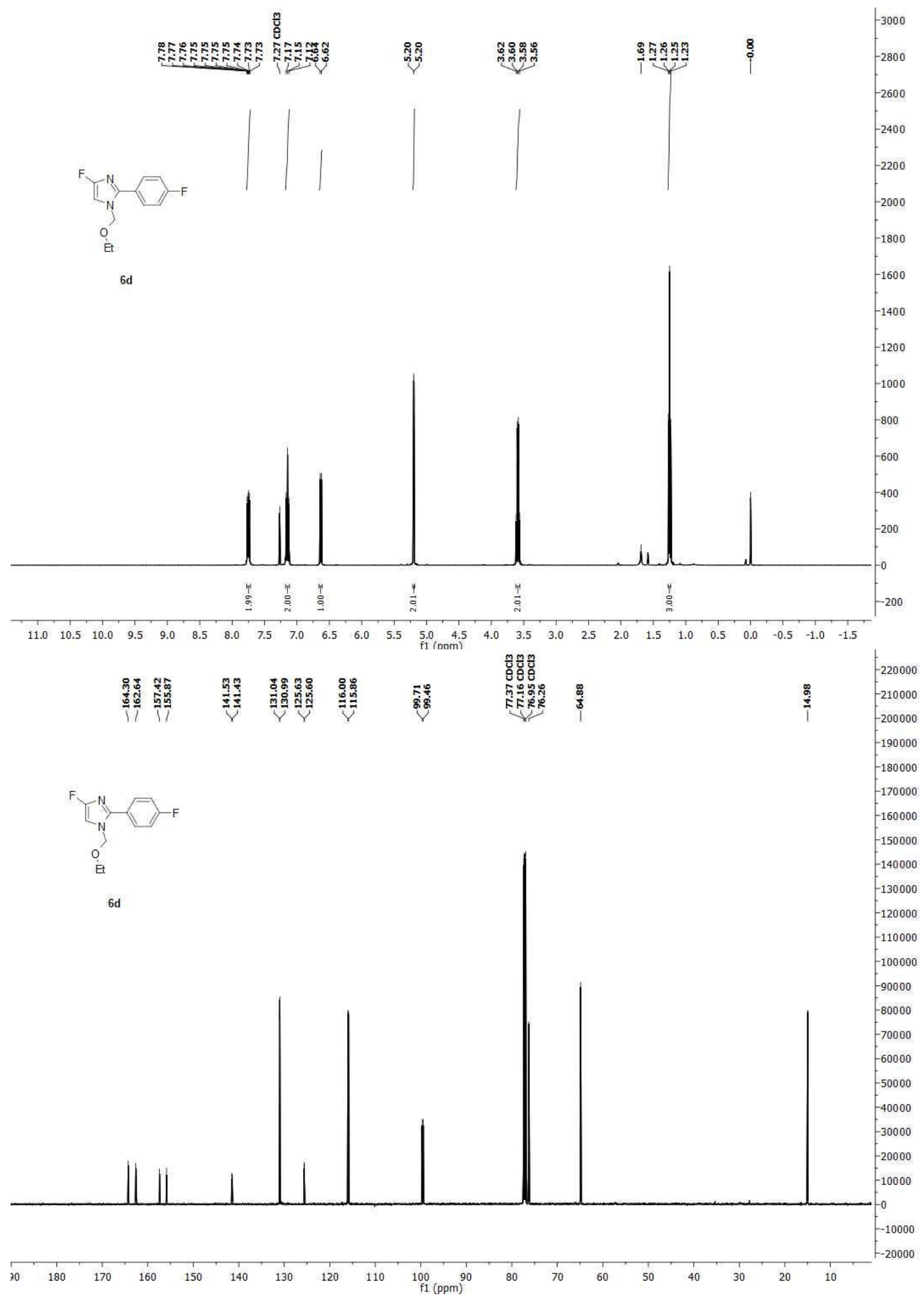




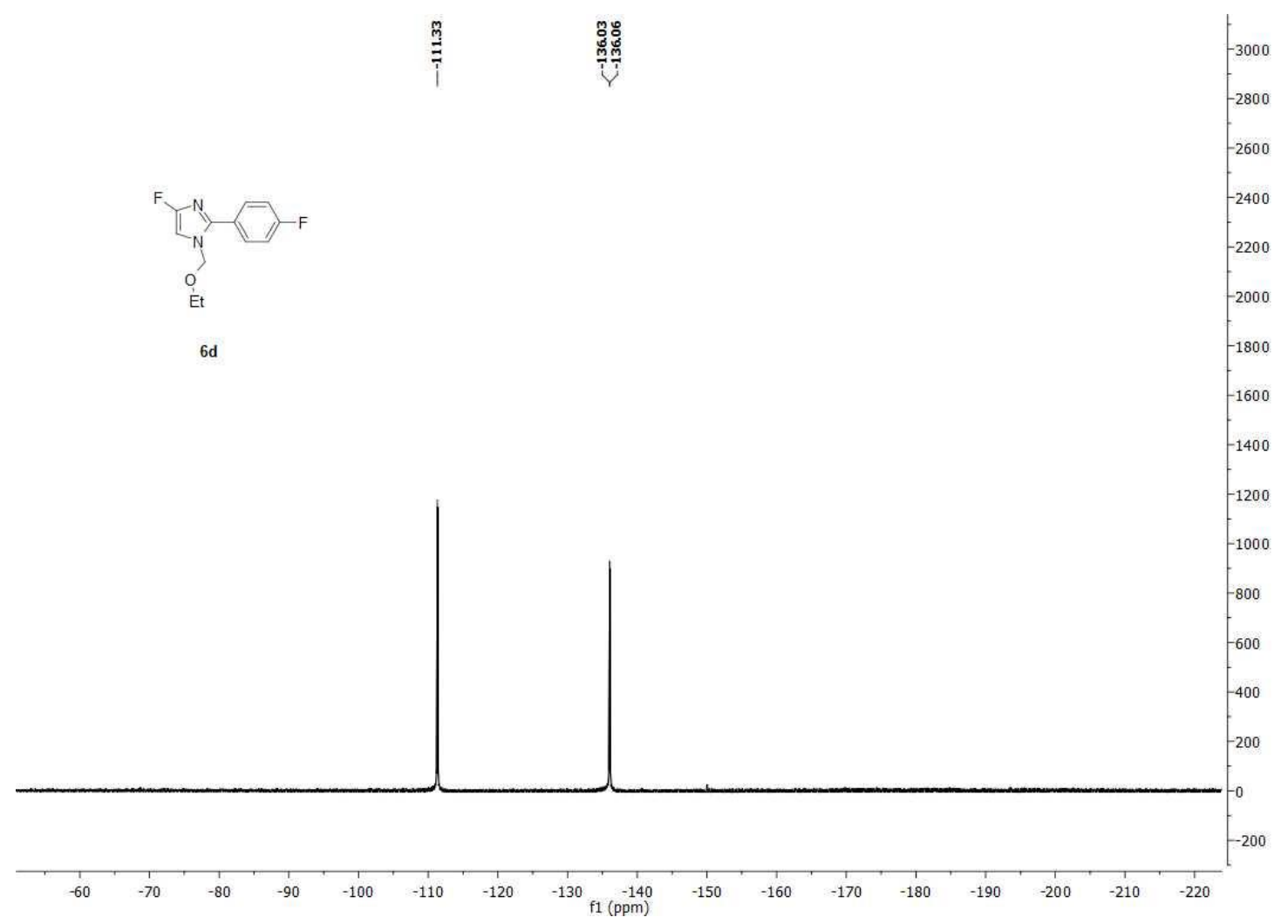

2-chloro-1-(ethoxymethyl)-1H-imidazole (1a).

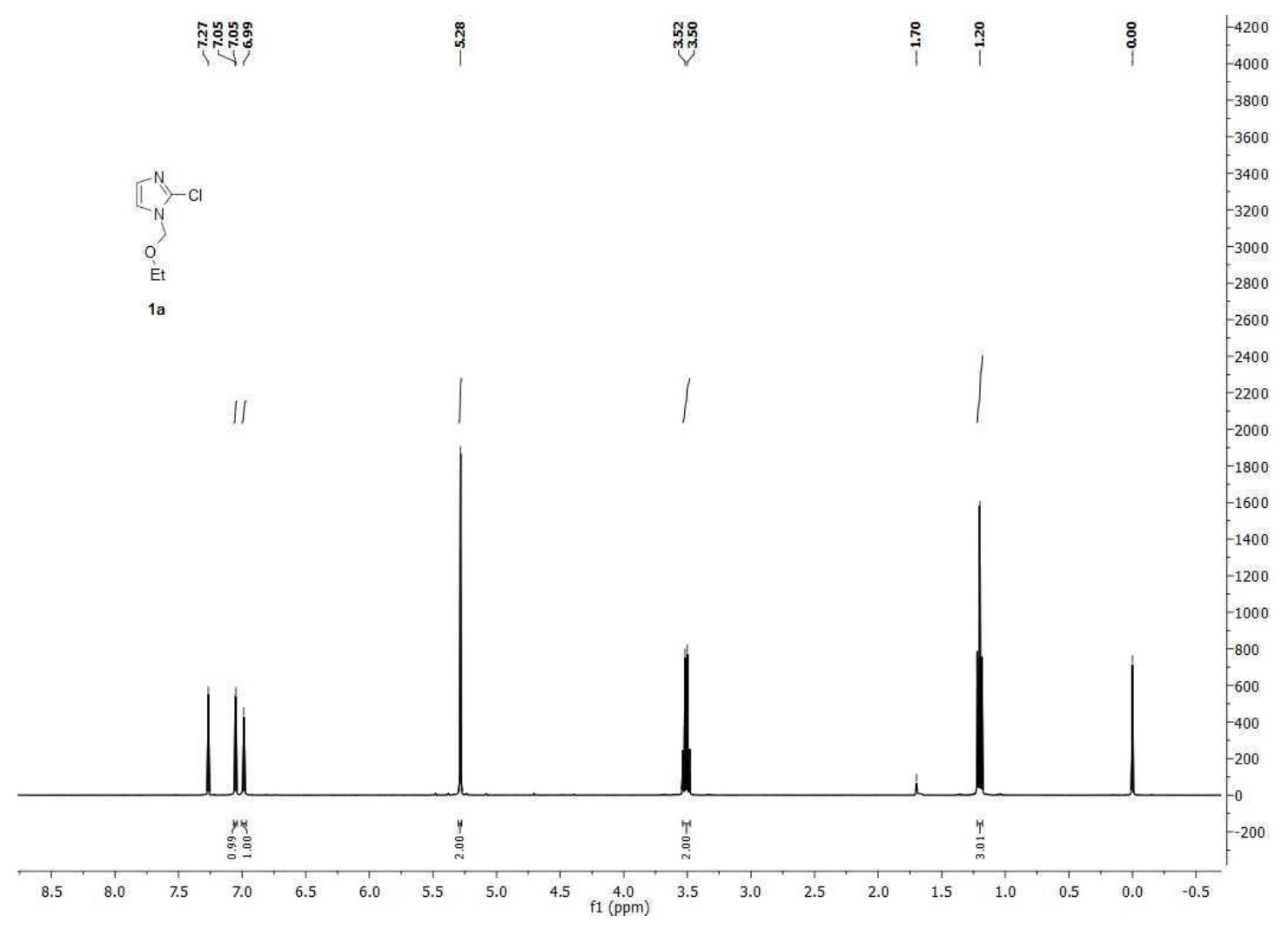




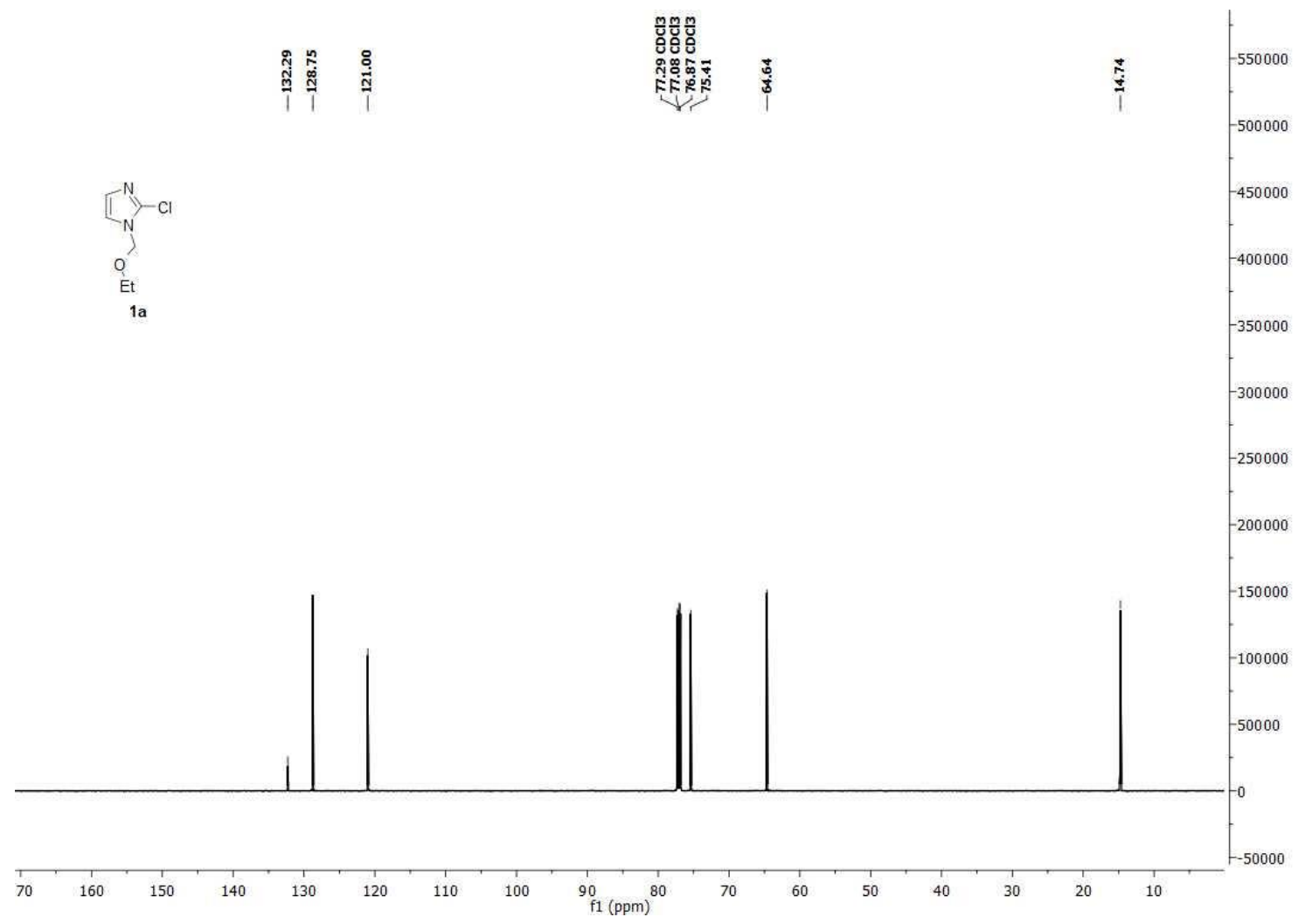

2-chloro-1-((2-(trimethylsilyl)ethoxy)methyl)-1H-imidazole (1b).

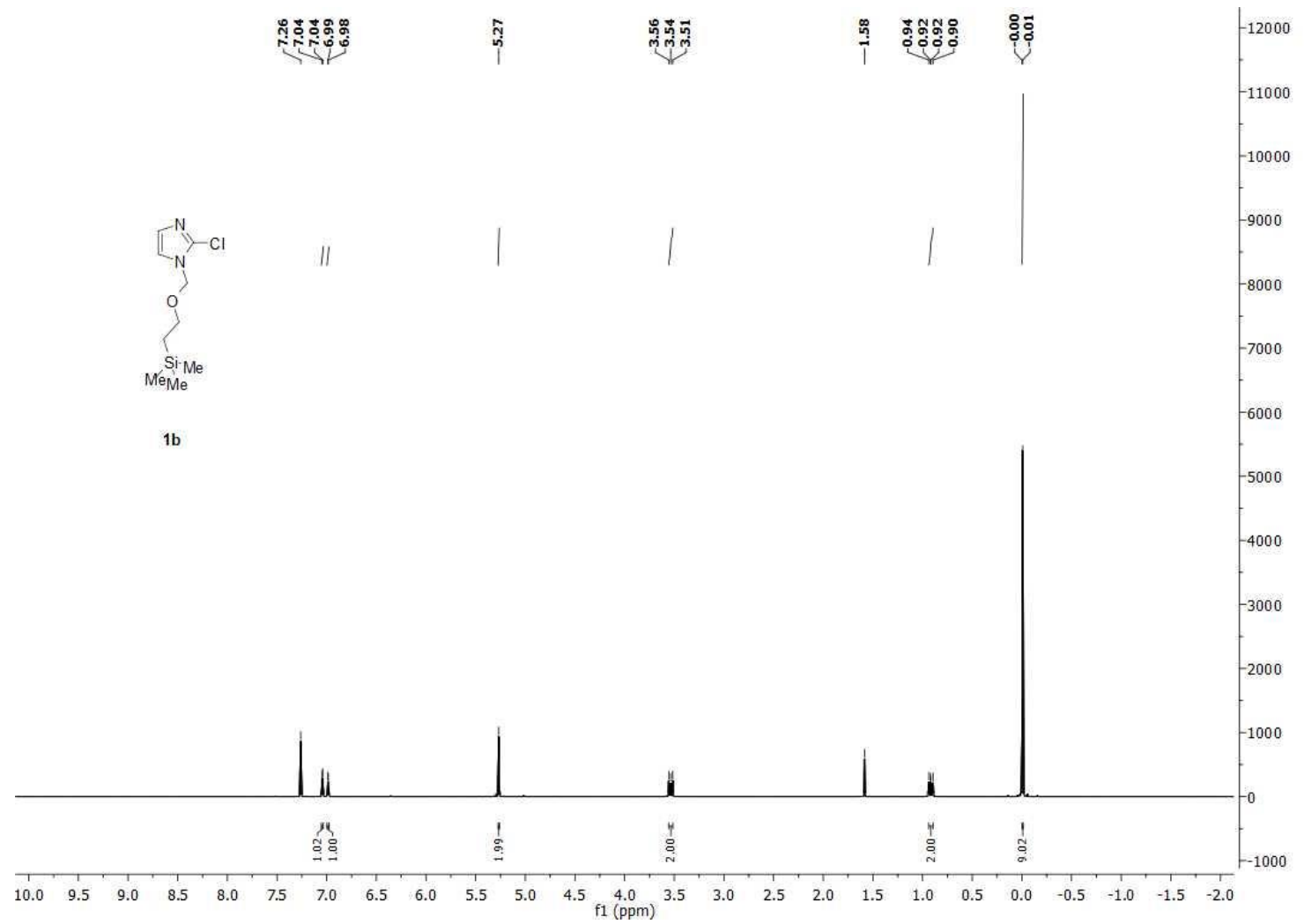




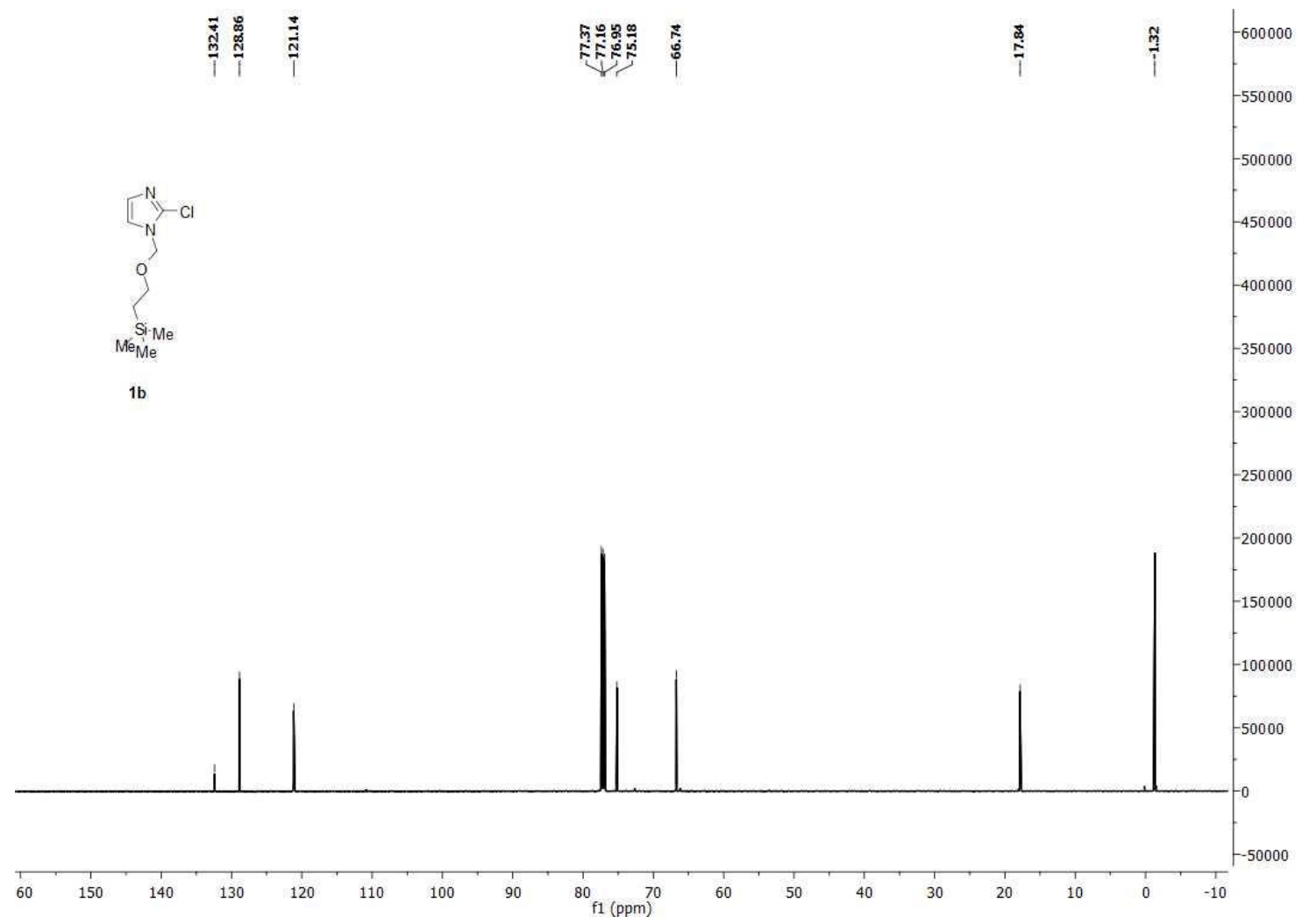

2-chloro-1-(1-ethoxyethyl)-1H-imidazole (1c).

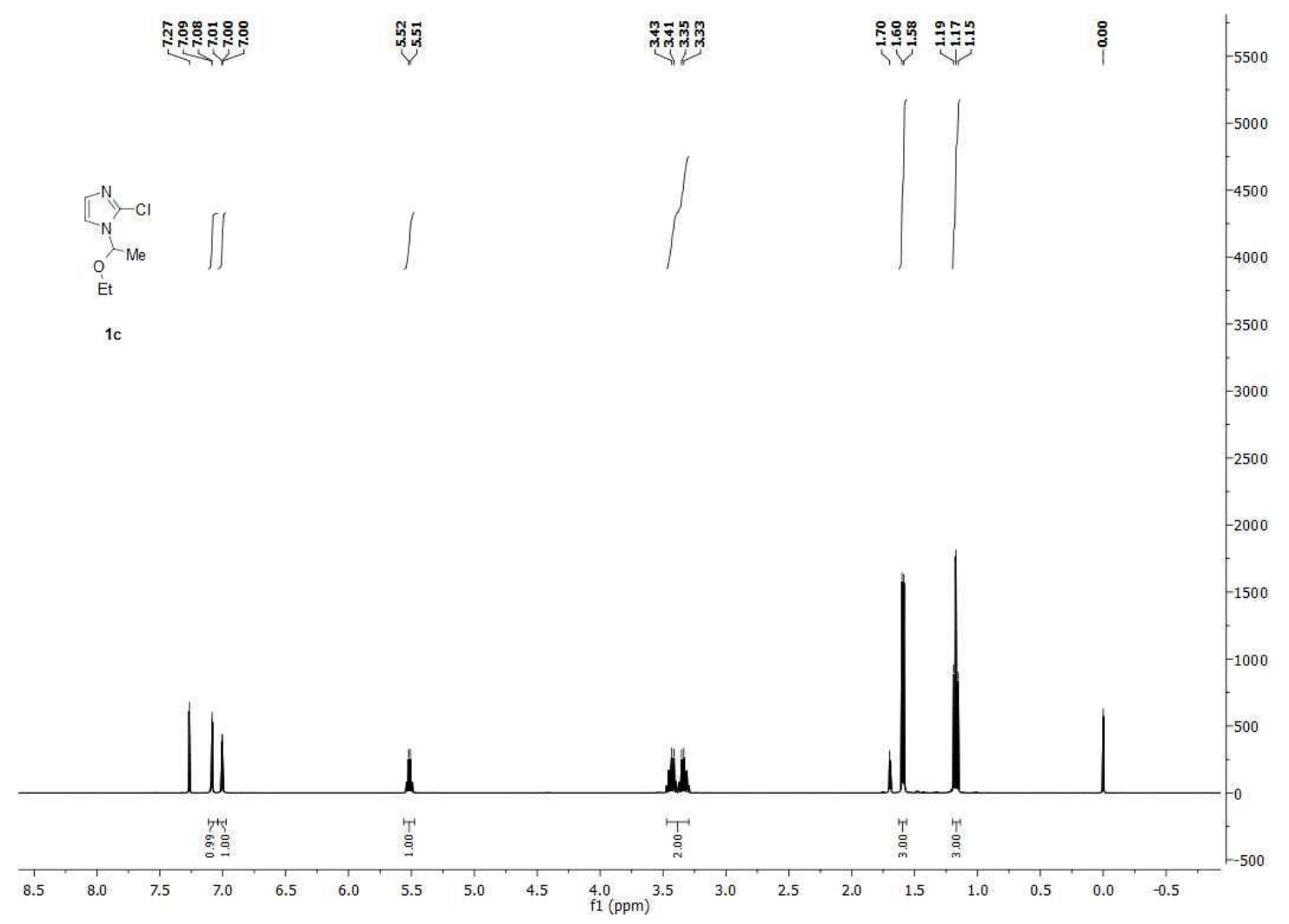



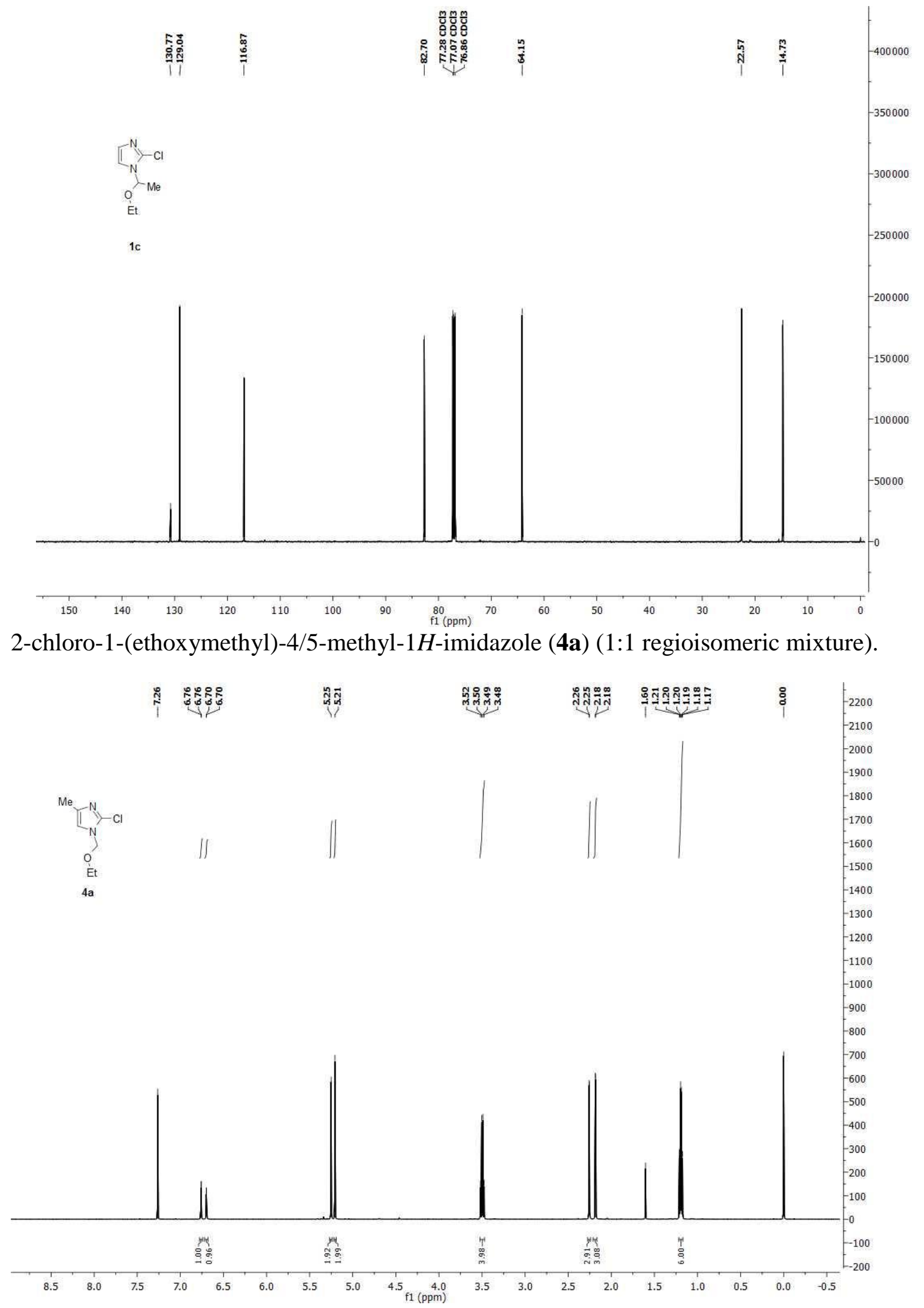


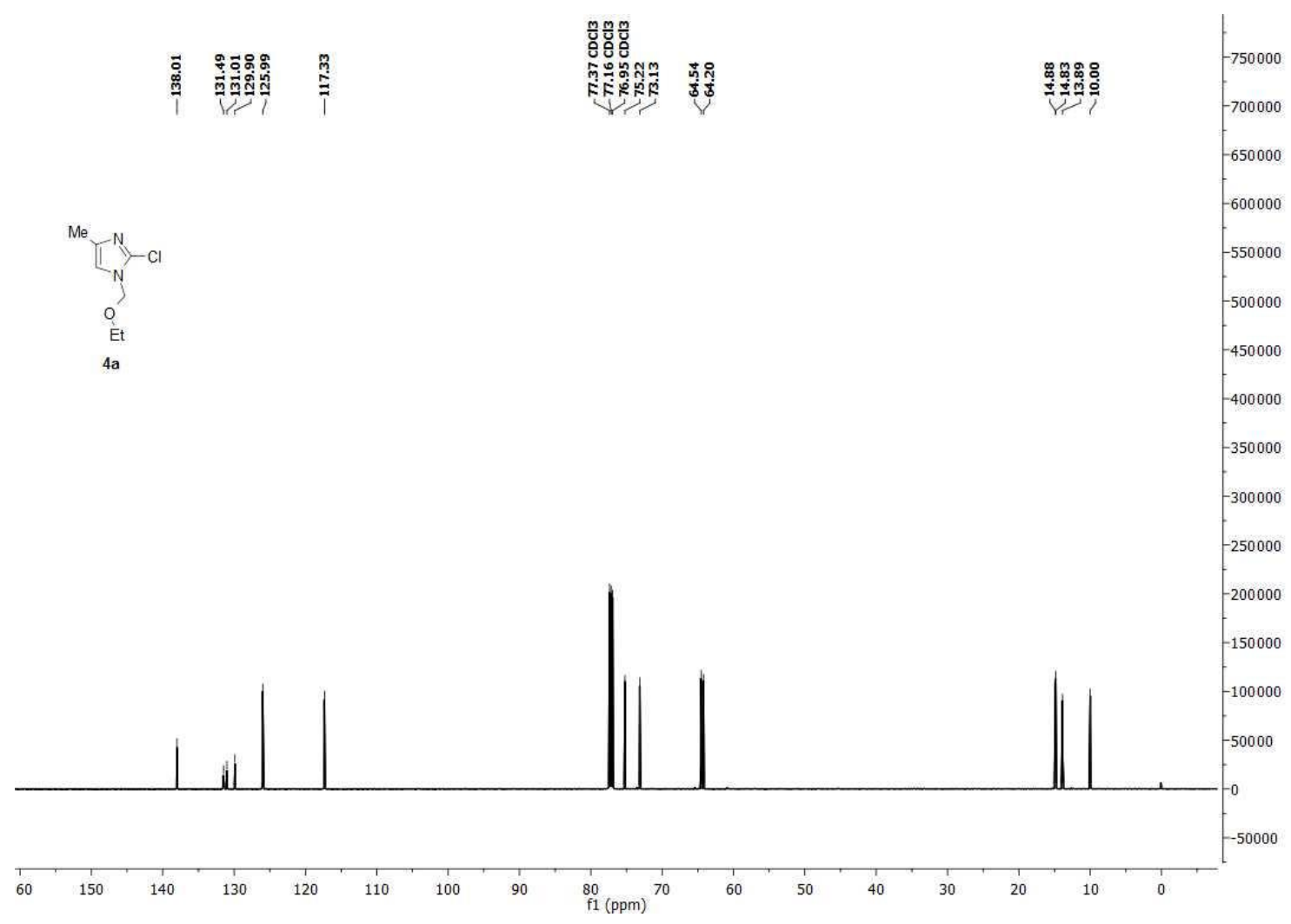

2-chloro-1-(ethoxymethyl)-4-phenyl-1 $H$-imidazole (4b).

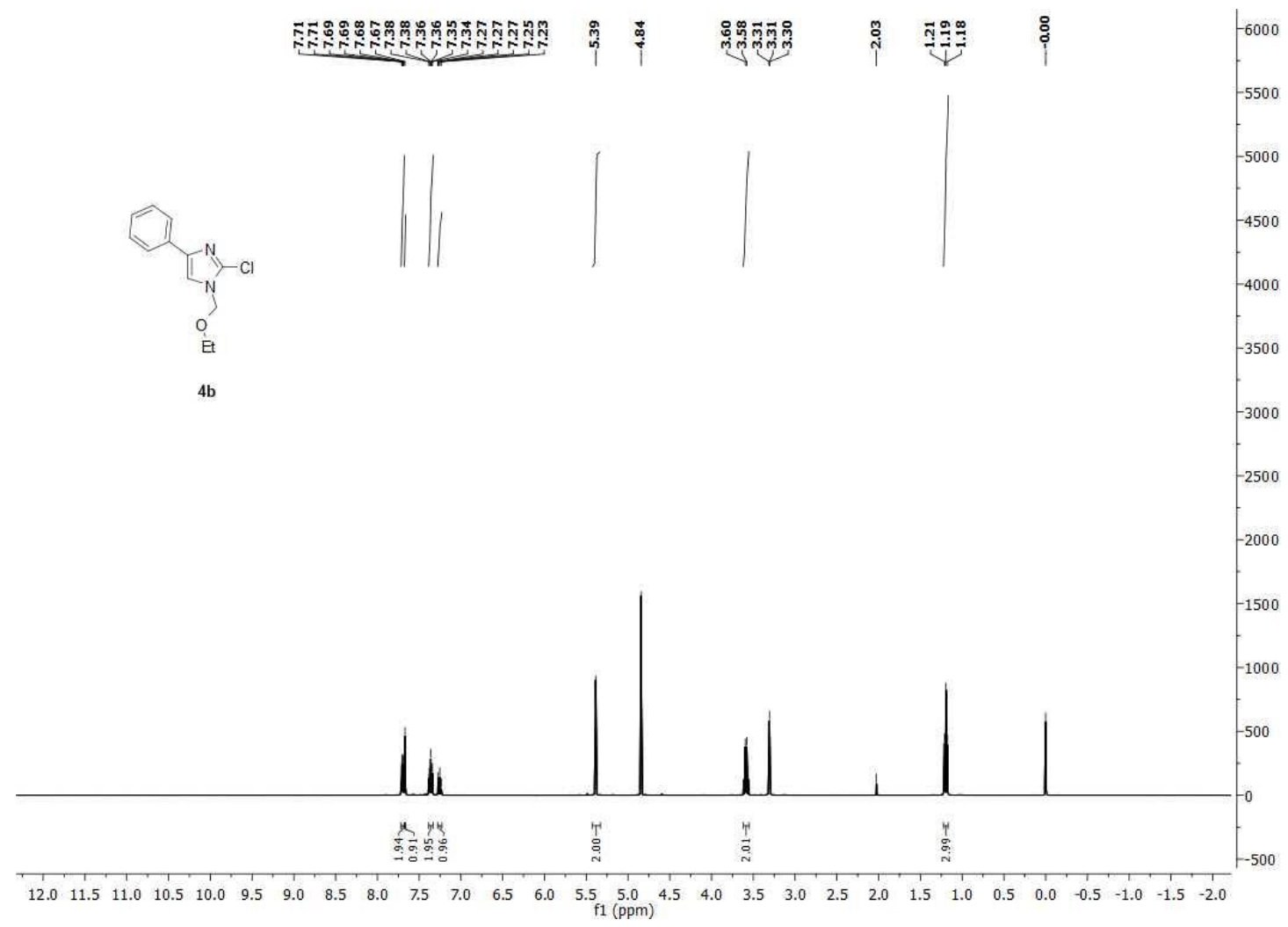




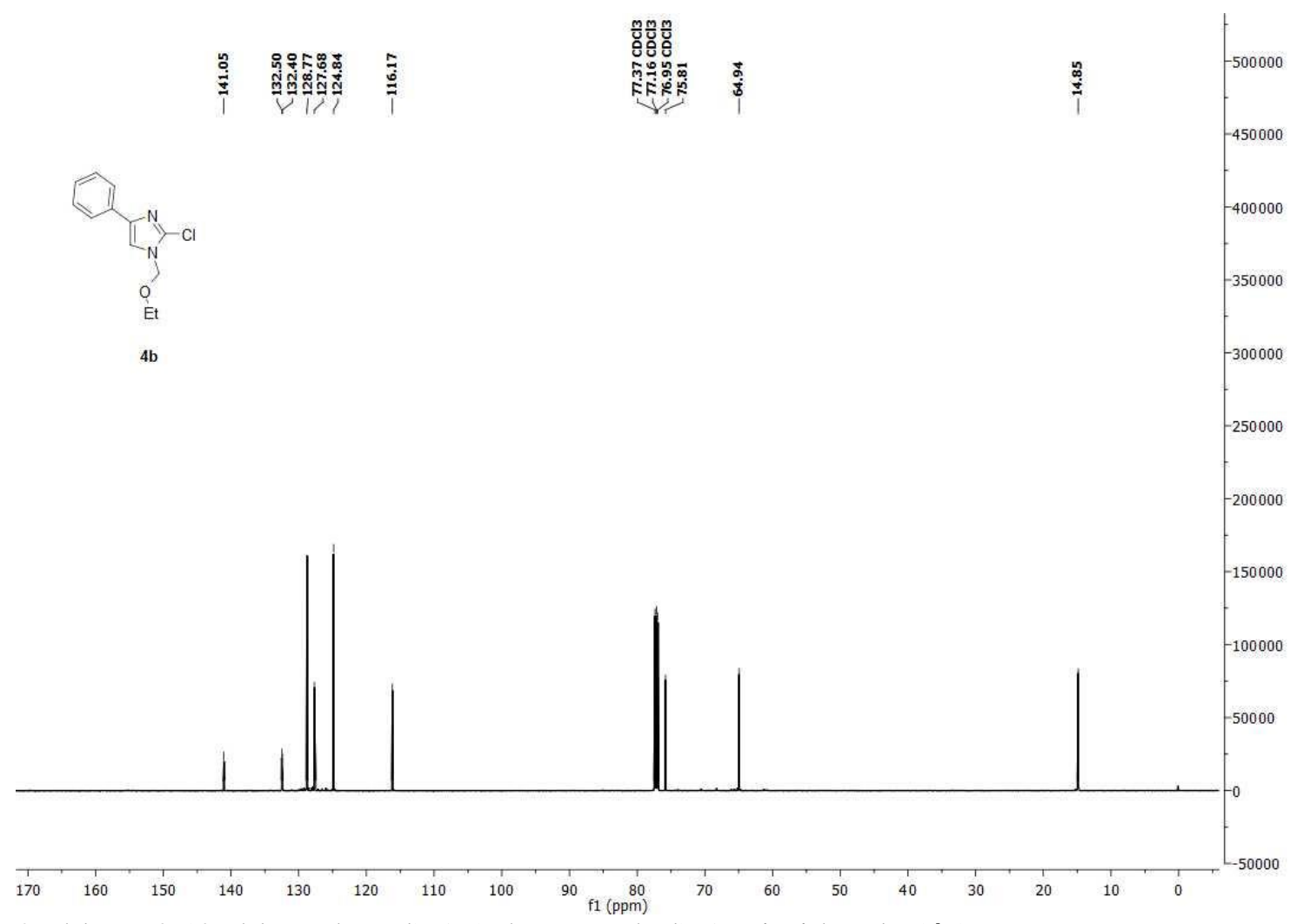

2-chloro-4-(4-chlorophenyl)-1-(ethoxymethyl)-1H-imidazole (4c).

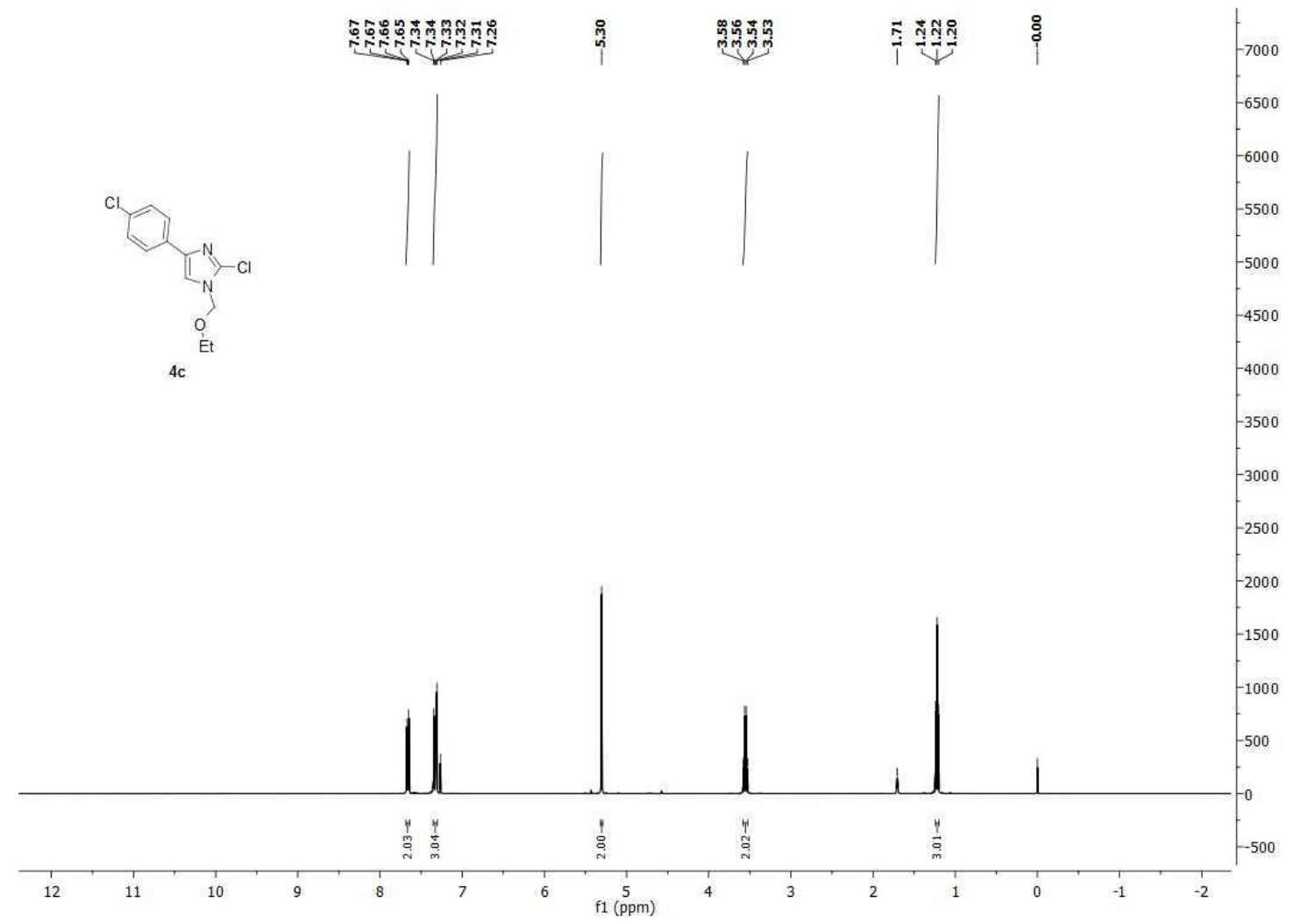




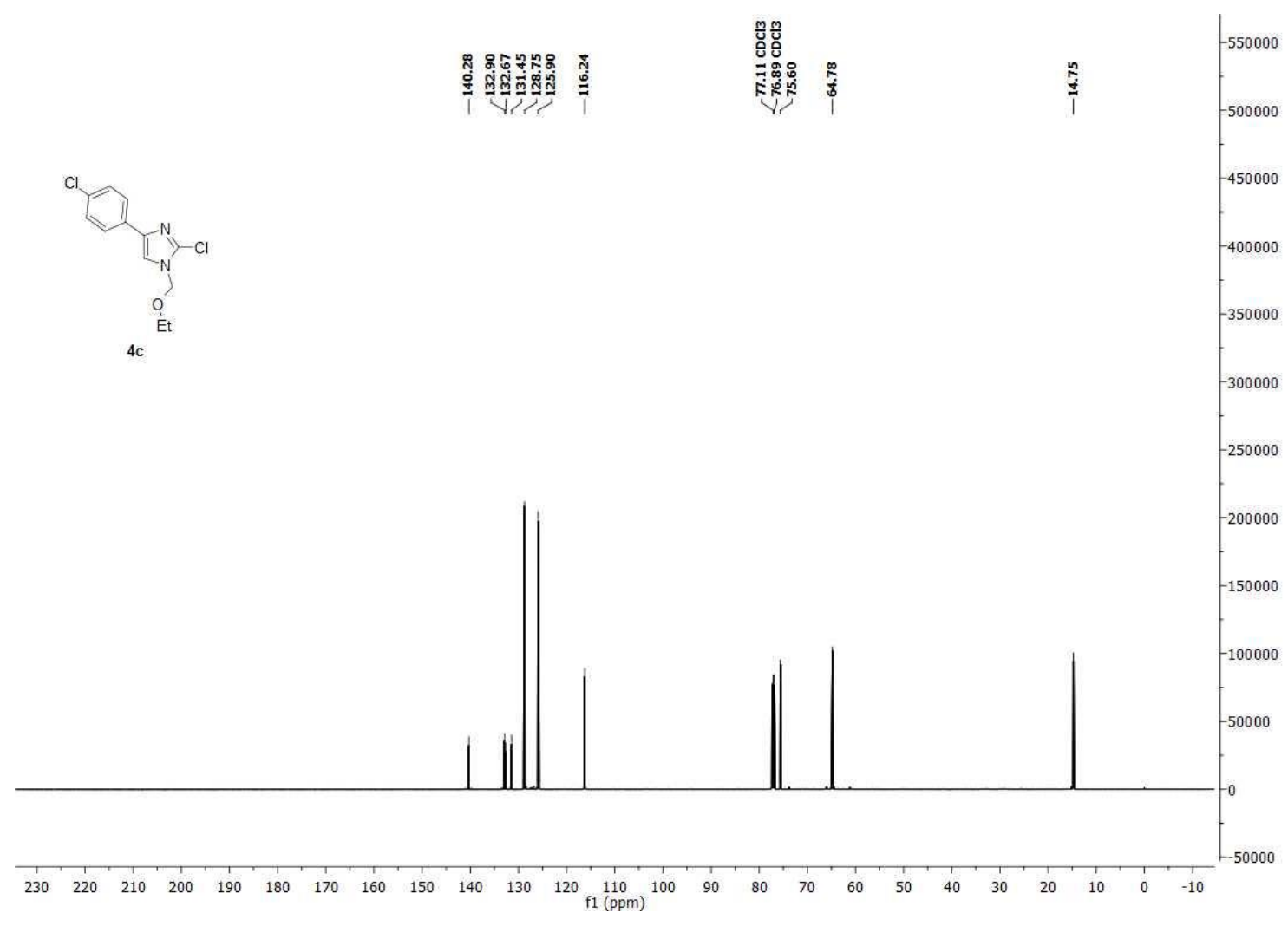

2-chloro-1-(ethoxymethyl)-4-(4-fluorophenyl)-1H-imidazole (4d).

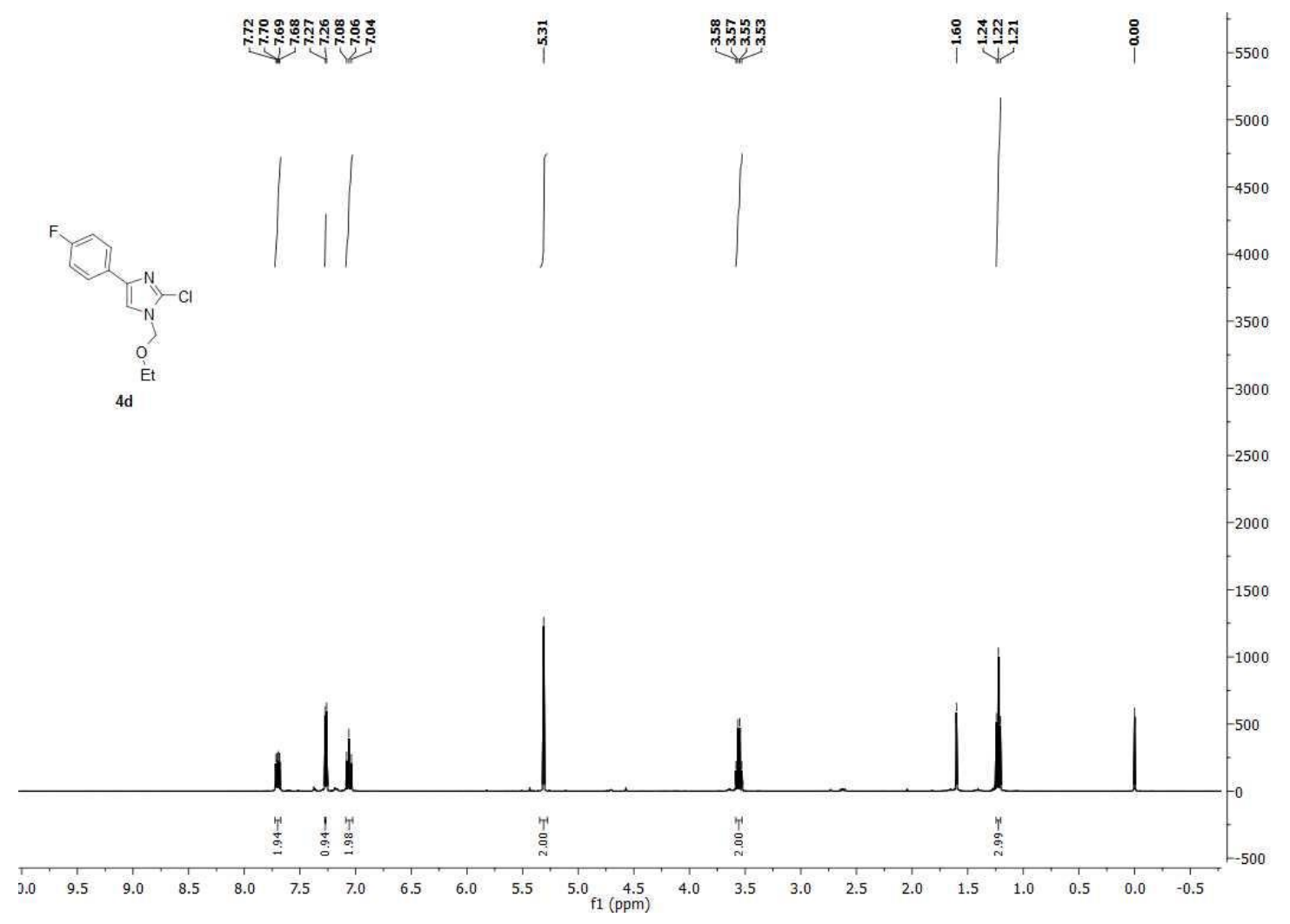




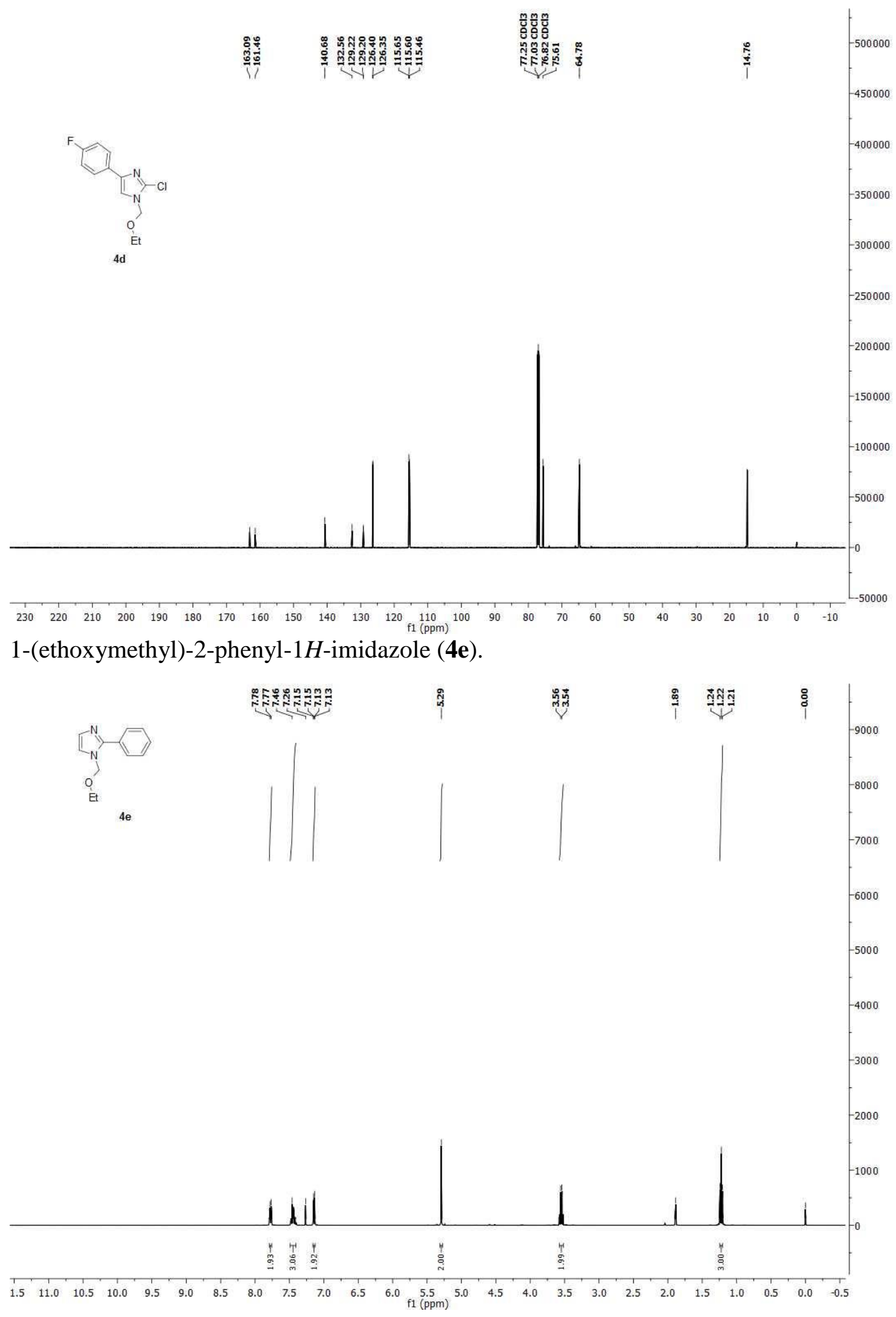




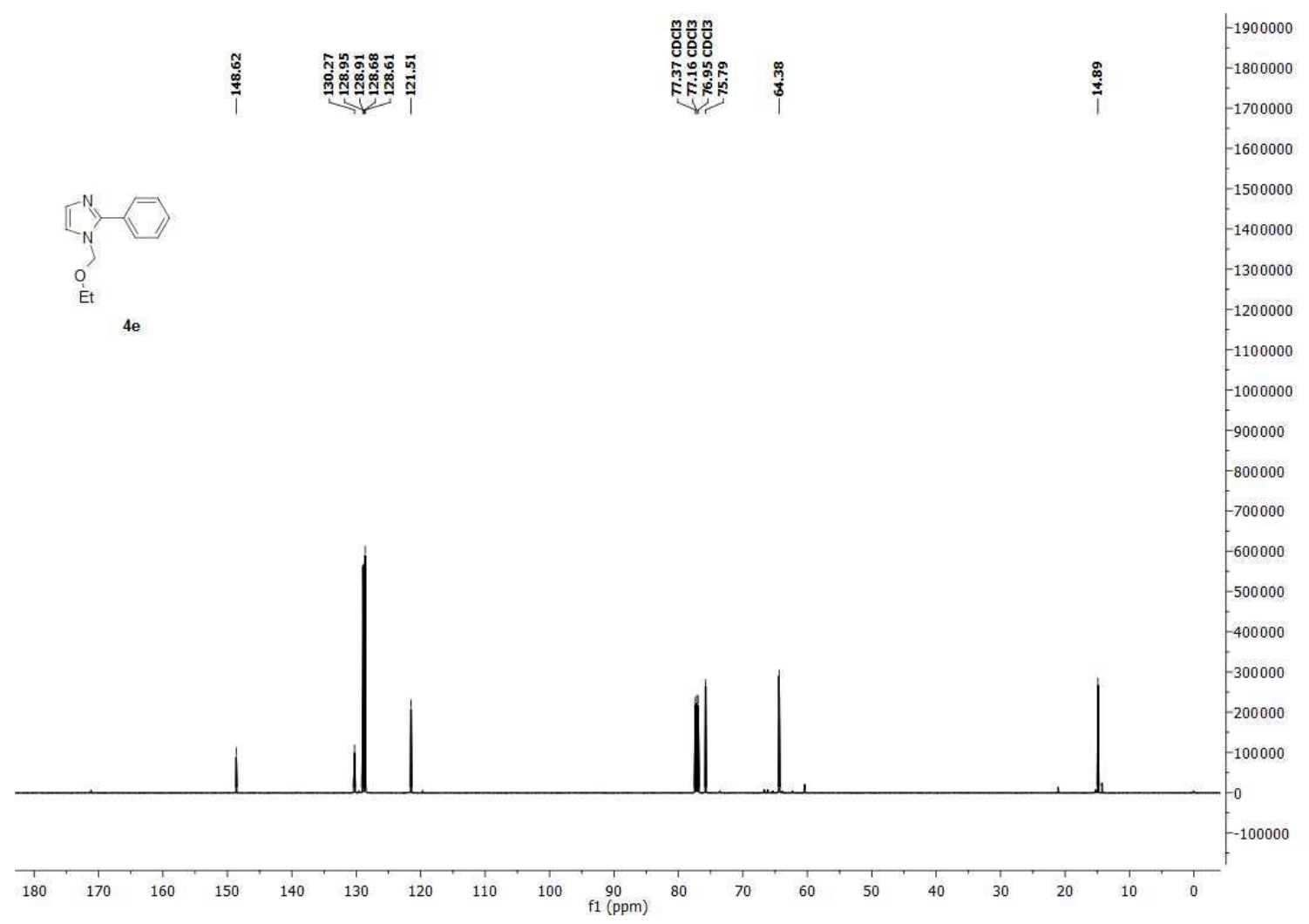

2-(4-chlorophenyl)-1-(ethoxymethyl)-1H-imidazole (4f).

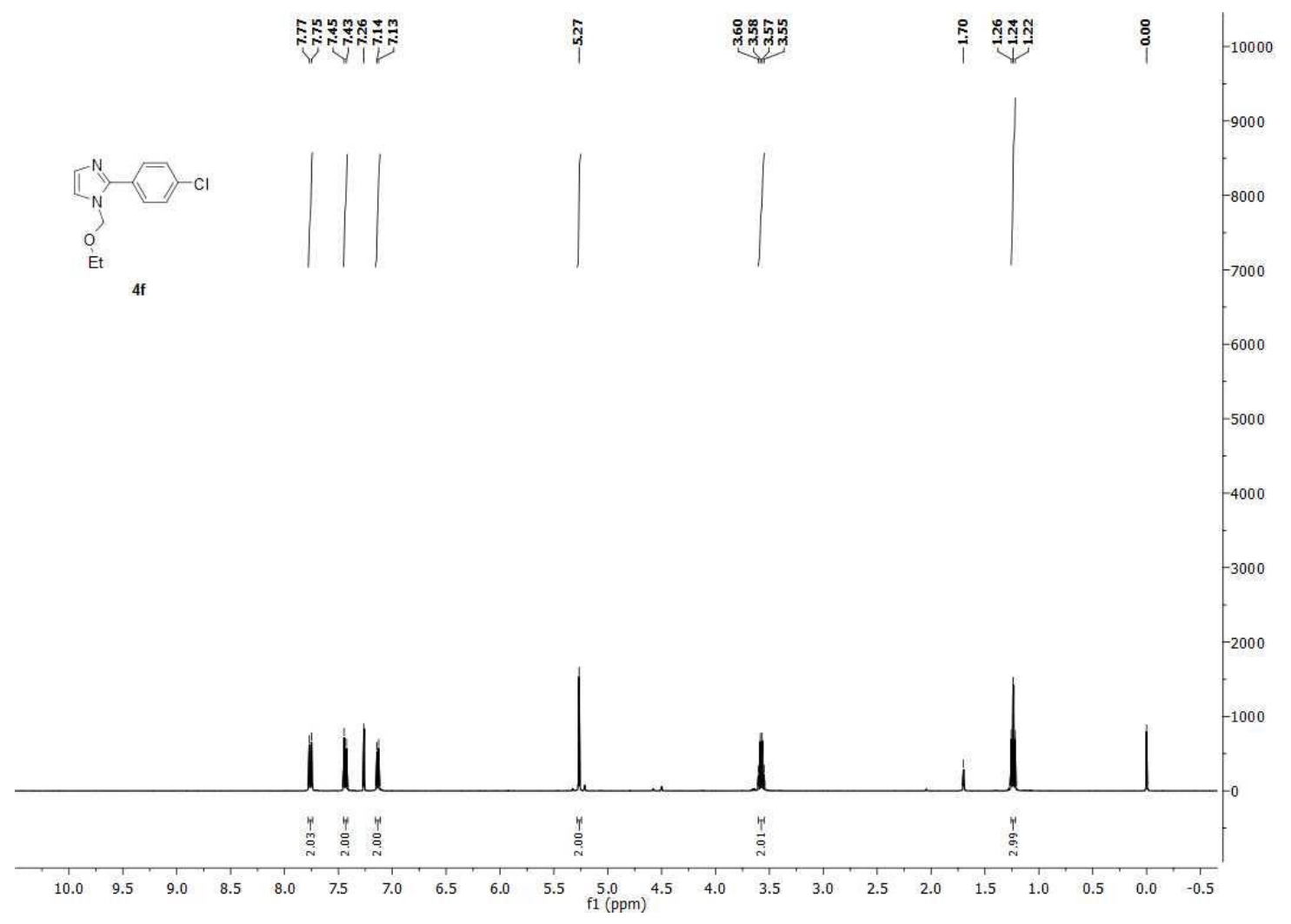




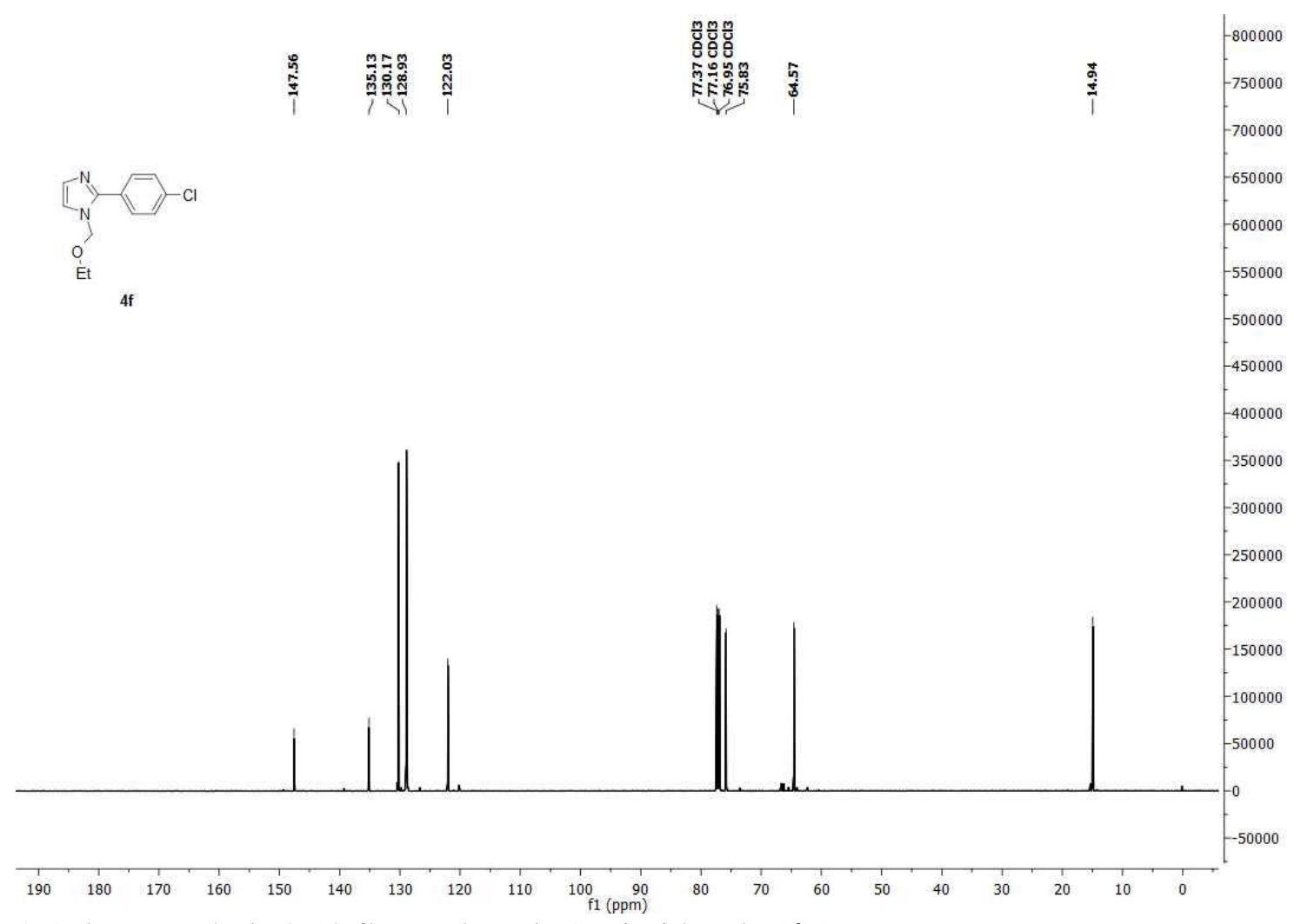

1-(ethoxymethyl)-2-(4-fluorophenyl)-1H-imidazole (4g).

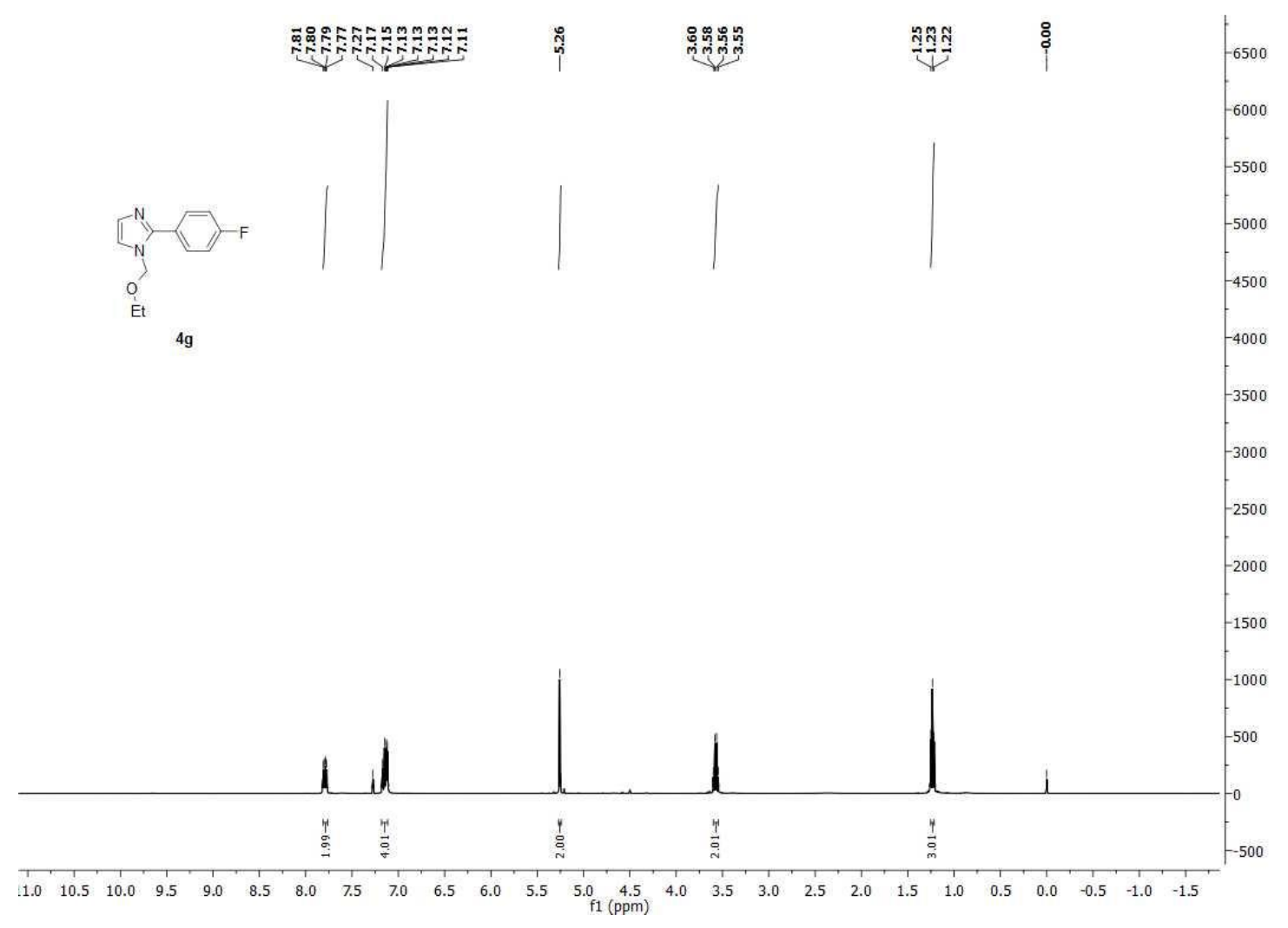




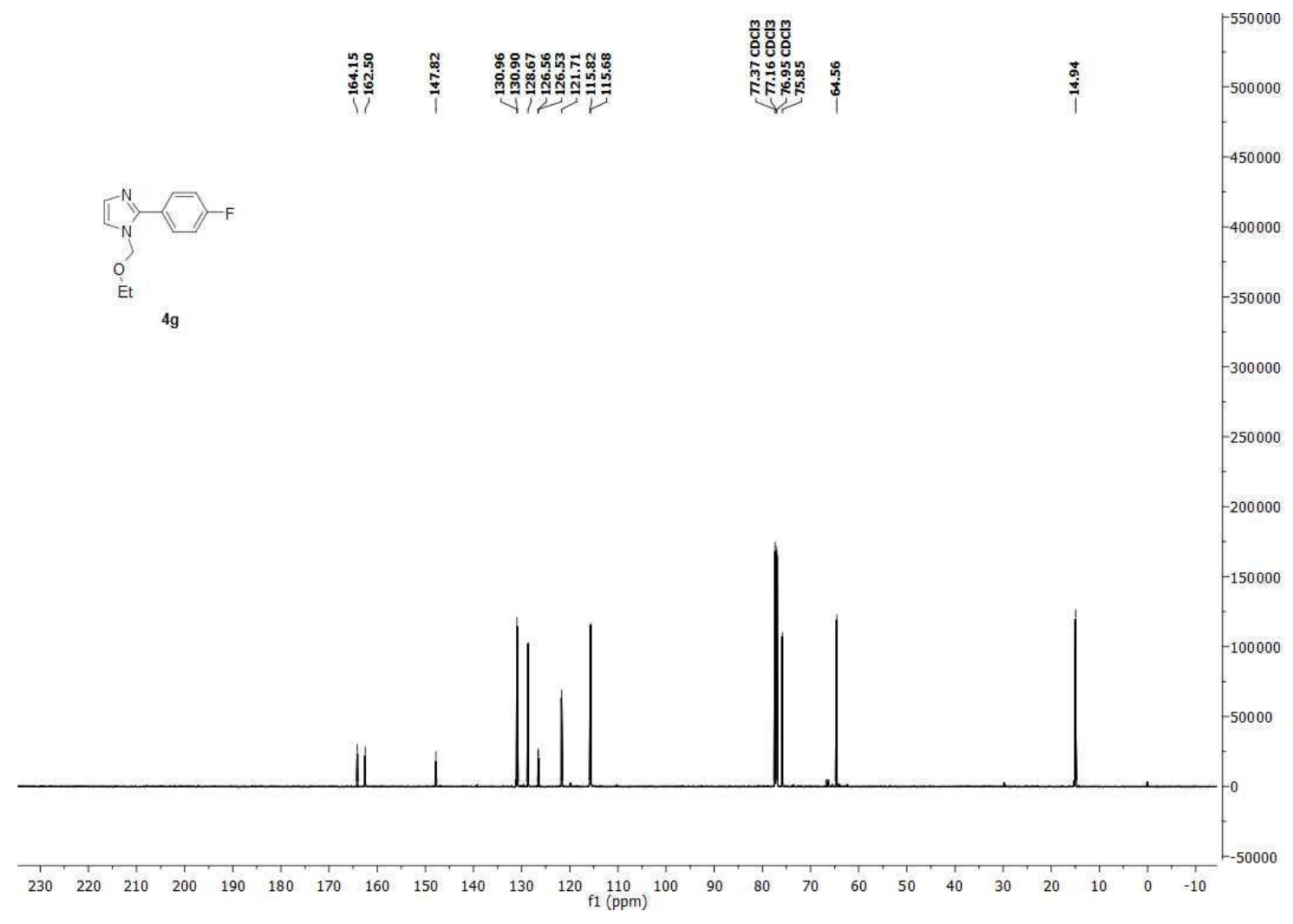

